\title{
Genome-wide deletion mutant analysis reveals genes required for respiratory growth, mitochondrial genome maintenance and mitochondrial protein synthesis in Saccharomyces cerevisiae
} Sandra Merz ${ }^{*}$ and Benedikt Westermann ${ }^{* \dagger}$ Addresses: *Institut für Zellbiologie, Universität Bayreuth, Universitätsstraße 30, 95440 Bayreuth, Germany. ${ }^{+B a y r e u t h e r ~ Z e n t r u m ~ f u ̈ r ~}$
Molekulare Biowissenschaften (BZMB), Universität Bayreuth, Universitätsstraße 30, 95440 Bayreuth, Germany.

Correspondence: Benedikt Westermann. Email: benedikt.westermann@uni-bayreuth.de

Published: 14 September 2009

Genome Biology 2009, 10:R95 (doi:10.1 186/gb-2009-10-9-r95)

The electronic version of this article is the complete one and can be found online at http://genomebiology.com/2009//0/9/R95
Received: 27 July 2009

Accepted: 14 September 2009

\section{(c) 2009 Merz and Westermann; licensee BioMed Central Ltd.}

This is an open access article distributed under the terms of the Creative Commons Attribution License (http://creativecommons.org/licenses/by/2.0), which permits unrestricted use, distribution, and reproduction in any medium, provided the original work is properly cited.

\begin{abstract}
Background: The mitochondrial respiratory chain produces metabolic energy by oxidative phosphorylation. Biogenesis of the respiratory chain requires the coordinated expression of two genomes: the nuclear genome encoding the vast majority of mitochondrial proteins, and the mitochondrial genome encoding a handful of mitochondrial proteins. The understanding of the molecular processes contributing to respiratory chain assembly and maintenance requires the systematic identification and functional analysis of the genes involved.
\end{abstract}

Results: We pursued a systematic, genome-wide approach to define the sets of genes required for respiratory activity and maintenance and expression of the mitochondrial genome in yeast. By comparative gene deletion analysis we found an unexpected phenotypic plasticity among respiratory-deficient mutants, and we identified ten previously uncharacterized genes essential for respiratory growth (RRGI through RRGIO). Systematic functional analysis of 319 respiratorydeficient mutants revealed 16 genes essential for maintenance of the mitochondrial genome, 88 genes required for mitochondrial protein translation, and 10 genes required for expression of specific mitochondrial gene products. A group of mutants acquiring irreversible damage compromising respiratory capacity includes strains defective in assembly of the cytochrome $c$ oxidase that were found to be particularly sensitive to aging.

Conclusions: These data advance the understanding of the molecular processes contributing to maintenance of the mitochondrial genome, mitochondrial protein translation, and assembly of the respiratory chain. They revealed a number of previously uncharacterized components, and provide a comprehensive picture of the molecular processes required for respiratory activity in a simple eukaryotic cell. 


\section{Background}

Mitochondria are the major sites of metabolic energy production in animals and most other eukaryotic organisms. Electrons generated by the oxidation of nutrients are passed along the respiratory chain and finally transferred to molecular oxygen in a process called oxidative phosphorylation. Energy released by the passage of electrons is stored as a proton gradient across the mitochondrial inner membrane and harvested by the ATP synthase to produce ATP from ADP and phosphate [1]. In an average human individual, ATP is synthesized at an astonishing rate of $9 \times 10^{20}$ molecules per second, totaling an amount of $65 \mathrm{~kg}$ per day [2]. In most eukaryotic organisms, the respiratory chain consists of five multi-subunit complexes: complex I, NADH dehydrogenase; complex II, succinate dehydrogenase; complex III, cytochrome bc $\mathrm{b}_{1}$ complex; complex IV, cytochrome $c$ oxidase; and complex V, ATP synthase [1]. In some organisms, including baker's yeast, Saccharomyces cerevisiae, complex I is replaced by an alternative $\mathrm{NADH}$ dehydrogenase that consists of a single amino acid chain $[3,4]$.

Biogenesis of the respiratory chain depends on coordinated expression of gene products encoded by the nuclear and mitochondrial genomes. The vast majority of the approximately 1,000 proteins that make up the mitochondrial proteome is encoded by nuclear genes, while a small number of proteincoding genes have been retained in the mitochondrial genome during the evolution of eukaryotic cells - thirteen in humans, eight in Saccharomyces cerevisiae, and as little as three in the protist Plasmodium falciparum [5]. Proteins encoded by the mitochondrial genome are generally restricted to a few respiratory chain complex subunits and - in some organisms - components required for synthesis and assembly of mitochondria-encoded proteins [5]. In order to express this handful of mitochondrial genes, the cell synthesizes about 200 nuclear-encoded proteins that are devoted to mitochondrial genome maintenance and gene expression $[6,7]$.

S. cerevisiae is a powerful model organism to genetically dissect the pathways required for maintenance of respiratory activity because it is capable of satisfying its energy requirements with ATP generated by fermentation. Thus, oxidative phosphorylation and the presence of the mitochondrial genome are dispensable as long as fermentable carbon sources, such as glucose or fructose, are present in the growth medium. Even when oxygen is available, yeast cells generate ATP primarily by glycolysis with ethanol as an end product of fermentation. Most respiratory functions are repressed under these conditions by catabolite repression [8]. Only when fermentable carbon sources become limiting, genes required for respiration are induced, and ATP is generated by metabolizing non-fermentable carbon sources, such as ethanol, glycerol or lactate $[9,10]$. Yeast mutants defective in oxidative phosphorylation are unable to grow on media containing non-fer- mentable carbon sources. On media containing limiting amounts of fermentable carbon sources, these mutants form smaller colonies than wild-type strains. The term petite has been coined to describe this characteristic phenotype [11]. The originally isolated petite mutants that were described in the 1940 s were later found to have long deletions in the mitochondrial genome (termed [rho-]) or completely lack mitochondrial DNA (termed $\left[\mathrm{rho}^{\circ}\right]$ ). Mutants with lesions in the mitochondrial genome are referred to as cytoplasmic petite, whereas respiratory-deficient strains carrying mutations in the nuclear genome are referred to as nuclear petite or pet mutants [12]. Nuclear pet genes include, but are not limited to, genes encoding respiratory chain components, factors required for folding and assembly of respiratory chain subunits, proteins required for mitochondrial DNA (mtDNA) inheritance, mitochondrial RNA and protein synthesis, and components of the machinery determining mitochondrial morphology [12-14].

By the end of the last century, more than 200 complementation groups and more than 100 pet genes had been identified by classic yeast genetic methods $[12,13,15]$. The availability of the yeast gene deletion library nowadays allows systematic and comprehensive screens to assign functions to almost all of the approximately 4,800 non-essential yeast genes [16]. Here, we aimed at a large-scale functional analysis of respiratory-deficient yeast mutants to define the complement of genes a yeast cell requires for mitochondrial gene expression and respiratory activity. Comparative gene deletion analysis revealed a surprising phenotypic plasticity of respiratorydeficient mutants and allowed us to identify ten novel genes that are essential for respiratory activity in yeast. By systematic functional tests of respiratory-deficient mutants we obtained a comprehensive picture of the molecular processes required for respiratory activity and maintenance and expression of the mitochondrial genome in yeast.

\section{Results and discussion Genes required for respiratory growth}

Two independent screens of the yeast deletion library have previously revealed two partially overlapping sets of pet genes. By plating the homozygous diploid yeast deletion library on media containing glycerol as a carbon source, Dimmer et al. [14] identified 341 deletion mutants that were unable to grow. In a very similar approach, Luban et al. [17] identified a set of 355 respiratory-deficient clones by screening the MATa yeast deletion library. While about two-thirds of the mutants in each screen were found to be respiratorydeficient also in the other screen, a surprisingly large number of mutants were isolated only once [17]. It seems unlikely that this is due to differences in the genetic background, because both screens have been conducted in largely isogenic strains, BY4743 and BY4741 [18]. Here, we screened the MAT $\alpha$ deletion library (BY4742 background) to obtain a third set of respiratory-deficient mutants. This was then compared with the 

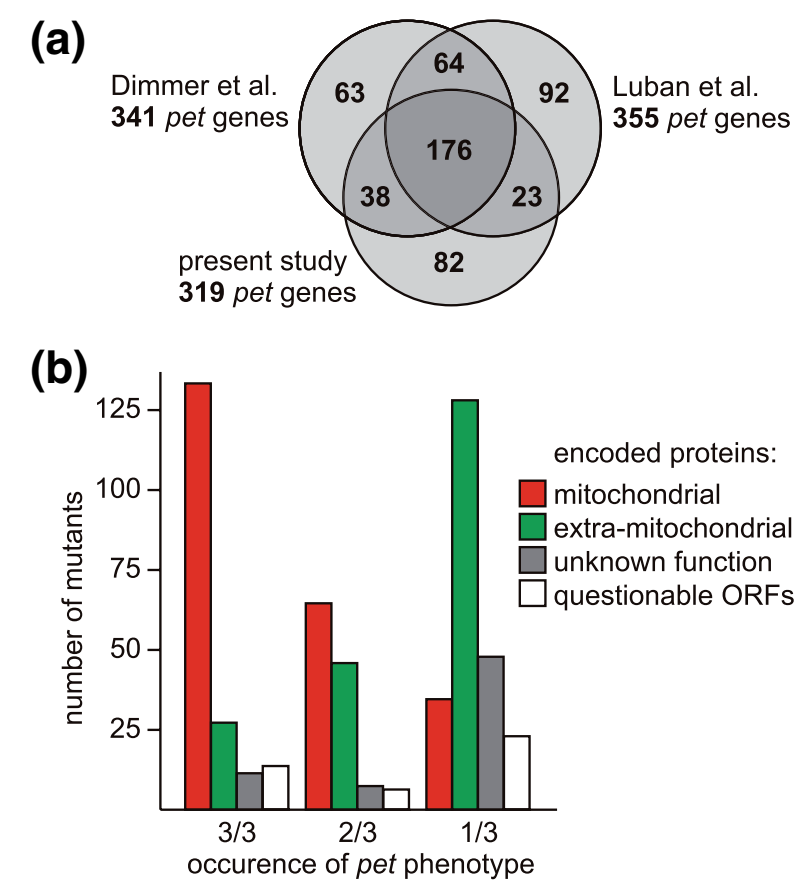

\section{(C) Nuclear pet genes of S. cerevisiae (176)}

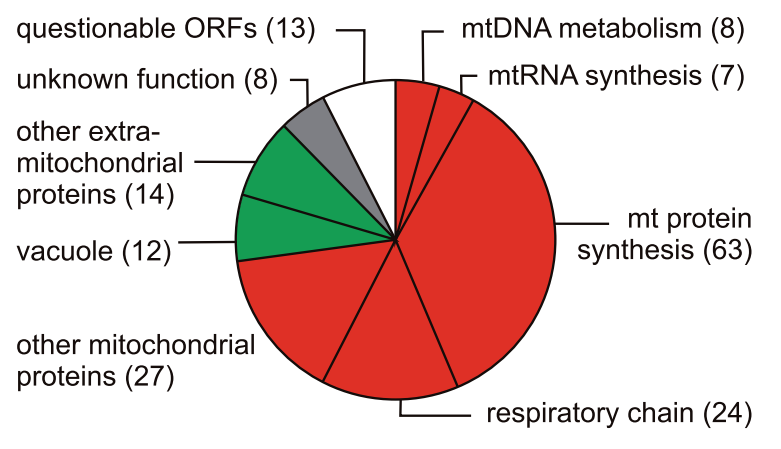

\section{Figure I}

Nuclear pet genes of $S$. cerevisiae. (a) The numbers of pet mutants identified in three screens of the yeast deletion library are indicated. References: Dimmer et al. [14], Luban et al. [17]. (b) The intracellular location of proteins encoded by pet genes has been grouped according to their frequency of occurrence in screens of the deletion library. The graph is a summary of data contained in Additional data file 3. (c) Cellular functions of proteins encoded by highly penetrant pet genes. Functions have been assigned according to data from the Saccharomyces Genome Database [19] and manual annotation. Red indicates mitochondrial proteins, green known extra-mitochondrial proteins, grey unknown proteins, and white dubious ORFs overlapping with known protein-coding genes.

data obtained by Dimmer et al. [14] and Luban et al. [17]. The $M A T \alpha$ deletion library contained 319 mutants that were unable to grow on glycerol-containing medium (Additional data file 1). Of these, 176 are common to all three sets of pet genes (Figure 1a). In the following we will refer to these genes as highly penetrant pet genes. 125 genes have been identified in two of three screens, and 237 genes have been identified only once (pet genes unique to this study are listed in Additional data file 2). Nineteen additional pet genes (not included in the set of 176 highly penetrant pet genes) were only covered by one or two libraries. Based on data from the Saccharomyces Genome Database [19] and manual annotation, we grouped all genes according to their frequency of occurrence in pet screens and the intracellular location and function of their gene products (Additional data file 3).

Strikingly, 129 out of the 176 pet genes found in all three screens encode proteins known to be located in mitochondria, corresponding to $73.3 \%$ (Figure $1 \mathrm{~b}$; Additional data file 3 ). The fraction of genes encoding mitochondrial proteins was reduced to $52.1 \%$ for pet genes found in two of three screens, and as low as $14.7 \%$ for pet genes that were found only once (Figure 1b; Additional data file 3). This demonstrates a clear correlation of the penetrance of pet phenotypes with mitochondrial functions of the affected gene products. The majority of the 176 pet genes found in all libraries encode proteins devoted to maintenance and expression of the mitochondrial genome and assembly of the respiratory chain (Figure 1c; Additional data file 3). Thirteen open reading frames (ORFs) are unlikely to encode proteins, because they overlap with other known genes (Additional data file 3), reducing the number of protein-coding genes to 163 .

Differences of growth behavior of strains taken from different versions of the deletion libraries could either reflect inherent properties of the mutant strains, they could be due to technical differences between the various screens, or they could mean that a given deletion in one collection is wrong (as it has occasionally been observed by us and others; for example, strains not correct in the MAT $\alpha$ library include $\Delta r p o 41$ lacking the mitochondrial RNA polymerase). We reasoned that incorrect mutants will be enriched among strains that showed respiratory competence in one screen but were respiratorydeficient in the two other screens because it is more likely that a specific phenotype is obscured rather than generated by chance. To test this, we checked the genotypes of 29 mutants taken from the MAT $\alpha$ library by PCR. Nineteen randomly chosen mutants were tested that were respiratory-competent in the MAT $\alpha$ library, but respiratory-deficient in the MATa and homozygous diploid library. Of these, six mutants ( $\Delta$ yalo12w, $\Delta y$ blo38w, $\Delta y d l 202 w, \Delta y d r 268 w, \Delta y o r 205 c$, and $\Delta y$ plo29w) contained exclusively the wild-type allele, seven mutants ( $\Delta y d r 231 c, \Delta y d r 332 w, \Delta y i l o 36 w, \Delta y j r o 9 o c$, $\Delta y m r o 66 w, \Delta y p r o 47 w$, and $\Delta y p r 124 w$ ) contained a mixture of deletion and wild-type alleles, and six mutants were found to have the correct genotype ( $\Delta y a l o 47 c, \Delta y b r 163 w$, $\Delta y d r 323 c, \Delta y k l 148 c, \Delta y m l o 81 c-a$, and $\Delta y m l 129 c)$. In addition, we tested ten mutants that showed a pet phenotype only in the MAT $\alpha$ library, but not in the MATa and homozygous diploid library, and ten mutants, that showed a pet phenotype in all three screens. All mutants of the two latter groups were found to have the correct genotype. This means whenever a wrong deletion was detected, a pet phenotype was obscured 
by the presence of the wild-type allele, whereas all respiratory-deficient mutants tested were found to have the correct genotype. We conclude that several discrepancies of growth phenotypes can be ascribed to wrong genotypes that are present in the deletion library. However, the fact that a relatively large number of mutants with confirmed correct genotypes show differences in their growth behavior points to a pronounced phenotypic plasticity of pet mutants. Furthermore, the correlation of the penetrance of pet phenotypes with mitochondrial localization of gene products (Figure 1b) is a clear indication that the phenotypic variability is not only due to wrong deletions present in the mutant libraries, but also reflects biological processes.

Eight highly penetrant pet genes (YDRo65w, YGR15oc, YJLO46w, YLLO33w, YLRO91w, YMR293c, YOR305w, and $Y P R 116 w)$ encode previously uncharacterized proteins, and earlier studies have revealed a respiratory-deficient phenotype for two additional ORFs of unknown function that were not covered by all three yeast deletion libraries, YNL213c [20] and YJLO62w- $a$ [21]. We confirmed the identity of these mutant strains by PCR and named the genes $R R G 1$ through $R R G 1 O$ (for 'Required for respiratory growth') as the functional analysis described below proves that their products are novel factors required for respiratory growth.

\section{Comparative growth analysis on different non- fermentable carbon sources}

We asked whether the respiratory-deficient phenotype observed for the 319 pet mutants isolated from the MAT $\alpha$ deletion library is specific to glycerol metabolism or reflects a general lack of respiration competence. To test this, we plated the mutants also on complete media containing lactate or ethanol as sole carbon sources. The vast majority (305 strains, corresponding to $95.6 \%$ of the pet mutants) failed to grow on all non-fermentable carbon sources that were tested. Of the remainder, seven mutants showed a growth defect only on glycerol-containing medium, seven on glycerol or ethanolcontaining media, and one mutant on glycerol or lactate containing media (Additional data file 4). As pet phenotypes are highly reproducible even on different carbon sources we conclude that our screen gives a largely accurate estimate of respiratory deficiencies in the $M A T \alpha$ deletion library.

\section{Restoration of respiratory activity by mating with $\Delta \mathrm{mipl}$ and by cytoduction of [ $\left.\mathrm{rho}^{+}\right]$mitochondria} In order to define the genetic basis of respiratory deficiency, we subjected the complete set of 319 pet mutants isolated from the MAT $\alpha$ deletion library to various functional tests (Figure 2). As a petite phenotype is often associated with the complete or partial loss of the mitochondrial genome [13], we first asked whether the pet mutants contain functional mtDNA. To test this, pet mutants were mated with a strain lacking the mtDNA polymerase Mip1. As the $\Delta$ mip1 strain is $\left[r h o^{\circ}\right]$ [22], resulting heterozygous diploid strains are able to grow on glycerol-containing medium only if functional

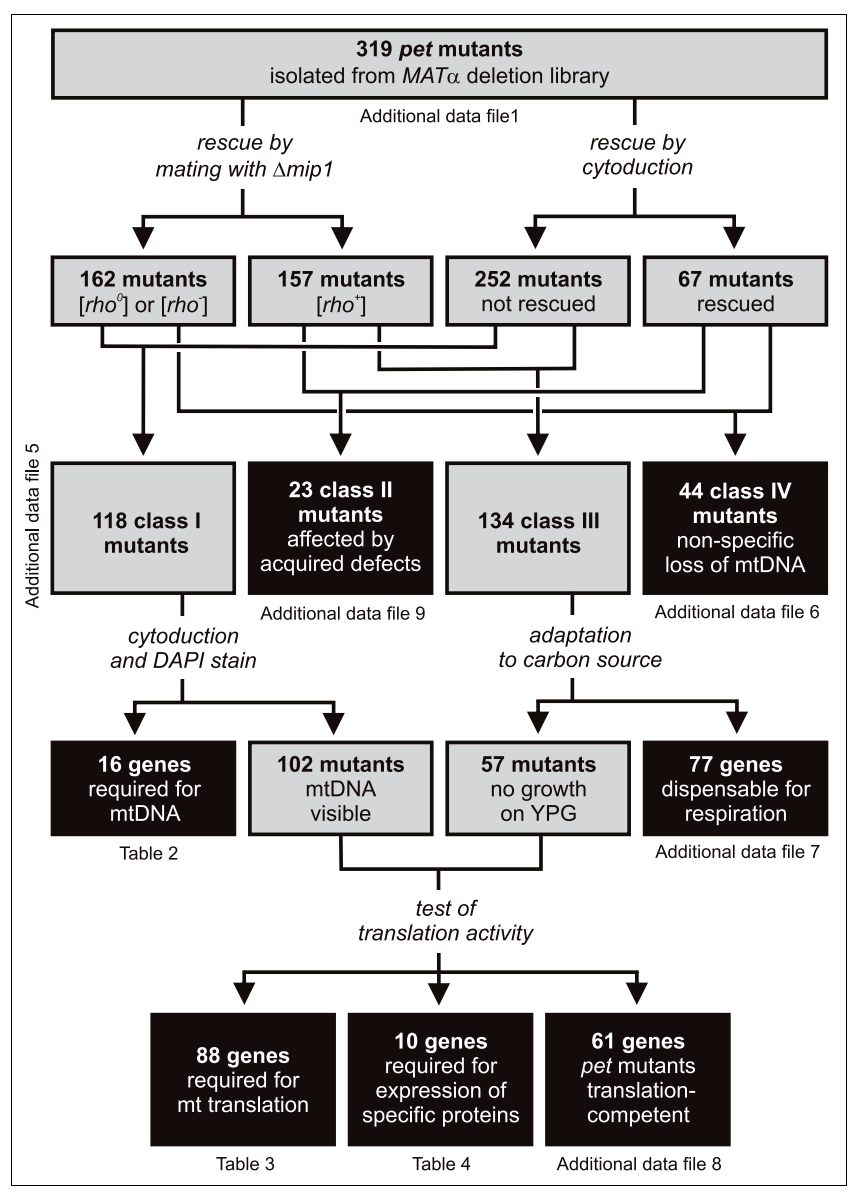

Figure 2

Summary of the systematic functional analysis of 319 pet mutants isolated from the MAT $\alpha$ yeast deletion library. Grey boxes indicate groups of mutants that were further analyzed, black boxes indicate the final level of resolution of functional analysis. See text for details.

mtDNA is provided by the pet mutant mating partner. We observed restoration of respiratory activity in 157 heterozygous diploid strains demonstrating that the parental pet strains possessed an intact mitochondrial genome. In contrast, 162 strains failed to grow on glycerol-containing medium after mating, suggesting that the parental pet mutants were $\left[\mathrm{rho}^{-}\right]$or $\left[\mathrm{rho}^{\mathrm{O}}\right]$.

The complementation test with $\Delta$ mip1 does not discern whether the protein encoded by the pet gene is obligatorily required for maintenance of mtDNA, or whether a functional mitochondrial genome had been spontaneously lost in the pet mutant during many generations of growth. To discriminate between these possibilities, we replenished cells with mitochondria containing a wild-type $\left[\mathrm{rho}^{+}\right]$mitochondrial genome by cytoduction. In brief, pet mutants were crossed with a $\left[\mathrm{rho}^{+}\right]$donor strain that carries a kar1 mutation to prevent karyogamy in the zygote. After counterselection against nuclear chromosomes of the donor strain, growth of the haploid progeny was assessed on glycerol-containing media. Res- 
toration of respiratory activity after cytoduction was observed in 67 pet mutants, whereas 252 strains failed to grow on nonfermentable carbon sources.

Combining the results from the $\Delta$ mip 1 mating test and the cytoduction experiment allowed us to define four classes of pet mutants (Figure 3; Additional data file 5). Class I mutants were not rescued either by mating with $\Delta$ mip 1 or by cytoduction; class II mutants were rescued by mating with $\Delta$ mip 1 as well as by cytoduction; class III mutants were rescued only by mating with $\Delta$ mip1, but not by cytoduction; and class IV mutants were rescued only by cytoduction, but not by mating with $\Delta$ mip1. The basic properties of these classes are summarized in Table 1 . In the following, the various classes of pet mutants are further examined (Figure 2).

\section{Genes required for maintenance of $\mathrm{mtDNA}$}

The 118 class I mutants were $\left[\mathrm{rho}^{-}\right]$or $\left[\mathrm{rho}^{\circ}\right]$ and remained respiratory-deficient after introduction of functional mitochondria. This group of mutants is expected to include all components that are essential for maintenance of a $\left[\mathrm{rho}^{+}\right]$ genome. In addition, we expected it to contain components deletion of which leads to a gradual loss of mtDNA and, at the same time, induces respiratory deficiency due to lack of functions not directly related to mtDNA maintenance. To discern between these possibilities, we subjected all class I mutants to various functional tests. First, we tested for the presence of mtDNA by DAPI (4',6-diamidino-2-phenylindole) staining immediately after cytoduction. Second, we tested growth on YPG medium after adaptation to the medium by pre-culture on YPG containing low amounts of glucose. And third, we tested mitochondrial protein translation activity by SDSPAGE and autoradiography after labeling cycloheximidetreated cells with $35 \mathrm{~S}$ methionine.

Genes essential for maintenance of mtDNA were defined by the following criteria: At least $95 \%$ of the cells observed by DAPI staining after cytoduction were devoid of mtDNA and the remainder contained less than five mtDNA nucleoids per cell. This phenotype was observed after cytoduction in the $\Delta$ mip1 mutant lacking the mtDNA polymerase and, therefore, is indicative of instantaneous loss of mtDNA. In addition, cells lacking genes essential for maintenance of mtDNA were expected to be unable to grow on YPG after adaptation to the carbon source, and they were unable to produce even trace amounts of mitochondria-encoded proteins. Sixteen mutants were identified that matched these criteria (Table 2). We propose that the gene products lacking in these mutants are particularly important for maintenance of mtDNA. As expected, this group includes several components known to be involved in mtDNA metabolism: the mtDNA polymerase Mip1 [22]; mtDNA helicases Hmi1 [23] and Pif1 [24]; Apn1, a DNA repair protein active in the nucleus and mitochondria [25]; and aconitase, Aco1, an enzyme of the citric acid cycle that has an additional role in mtDNA maintenance [26].

It has been observed that a block of mitochondrial protein synthesis leads to a rapid and quantitative loss of mtDNA [27]. However, the reasons for this phenomenon are still unknown. Here, we observed instantaneous loss of mtDNA in cells lacking Mrpl37, Mtf1, Mtg2, Rsm24, and Slm5, which are all required for mitochondrial transcription or translation, and in a deletion mutant lacking the dubious ORF $Y K L O 91 w$, which overlaps with the MRPL38 gene encoding a mitochondrial ribosomal protein. Loss of mtDNA at a relatively high rate was also observed in several other class I mutants lacking components of the mitochondrial protein synthesis machinery. These findings underscore the importance of mitochondrial protein synthesis for maintenance of mtDNA. Moreover, rapid loss of mtDNA was observed in the satp4 mutant lacking ATPase subunit b. This is consistent with earlier observations [28]; however, the molecular reasons are not understood [29]. Also, $\Delta$ pet1oo mutants lacking a factor required for cytochrome $c$ oxidase assembly showed rapid loss of mtDNA. As loss of mtDNA in $\Delta a t p 4, \Delta m r p l 37$, $\Delta m t f 1, \Delta m t g 2, \Delta p e t 10 O, \Delta r s m 24$, and $\Delta s m_{5}$ occurs instantaneously (as rapid as in $\Delta$ mip1) we consider it likely that replication and/or inheritance of mtDNA is actively suppressed in these strains. These results point to an active role of Atp4, Mrpl37, Mtf1, Mtg2, Pet10o, Rsm24, and Slm5 in regulating mtDNA abundance in yeast mitochondria.

Table I

Classes of pet mutants

Class Respiration after mating with $\Delta$ mip I Respiration after cytoduction Associated gene functions

\begin{tabular}{|c|c|c|c|}
\hline I & - & - & $\begin{array}{l}\text { Genes essential for maintenance of mtDNA ( } 16 \text { mutants); } \\
\text { or genes essential for respiration with gradual loss of } \\
\text { mtDNA ( } 102 \text { mutants) }\end{array}$ \\
\hline II & + & + & $\begin{array}{l}\text { Additional effects of extra-genomic factors and/or acquired } \\
\text { mitochondrial damage ( } 23 \text { mutants) }\end{array}$ \\
\hline III & + & - & $\begin{array}{l}\text { Genes essential for respiration but not for maintenance of } \\
\text { mtDNA (I } 34 \text { mutants) }\end{array}$ \\
\hline IV & - & + & $\begin{array}{l}\text { Genes dispensable for respiration, gradual loss of mtDNA } \\
\text { (44 mutants) }\end{array}$ \\
\hline
\end{tabular}




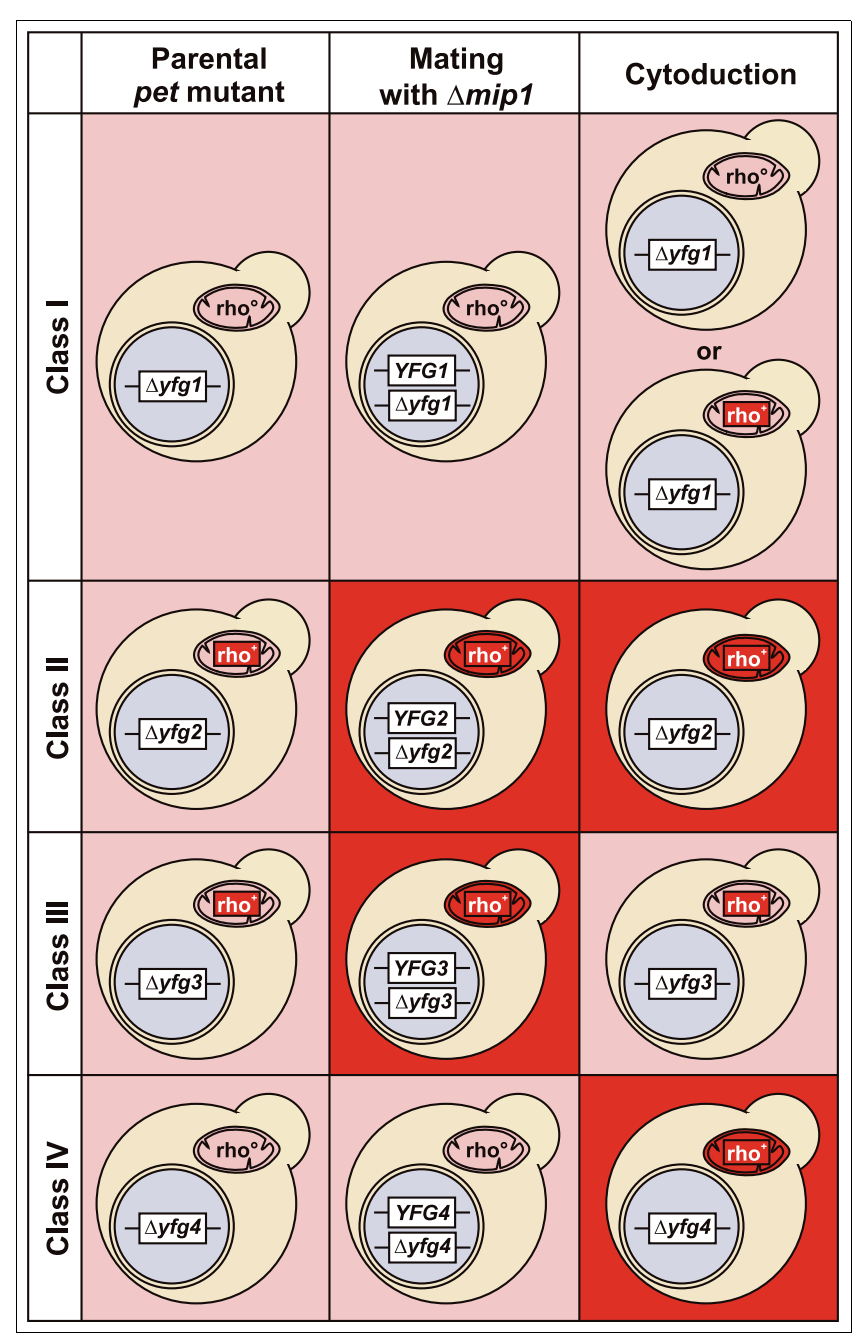

Figure 3

Classes of pet mutants. The left column indicates genotypes of haploid pet mutant strains taken from the deletion library carrying a deletion in the nuclear genome ( $\Delta y f g I$, 'your favourite gene I') and either no mtDNA ( $\left[r^{\circ} 0^{0}\right]$; alternatively these strains might be $\left[\right.$ rho- $\left.^{-}\right]$) or a wild type-like mitochondrial genome ([rho+ ${ }^{+}$; labeled in red). The middle column indicates genotypes of heterozygous diploid strains after mating with $\Delta$ mipl. The right column indicates genotypes of haploid deletion mutants after having received $\left[\mathrm{rho}^{+}\right]$mitochondria from a donor strain by cytoduction. Respiratory-competent mitochondria are labeled in red, and respiratory-competent yeast cells are depicted on a red background. Class I mutants contain either $\left[\mathrm{rho}^{+}\right]$or $\left[\mathrm{rho}^{0}\right]$ or $\left[\mathrm{rho}^{-}\right]$mitochondria after cytoduction. See text for details.

Other factors required for mtDNA inheritance are Mgm1, Doc1 and the newly identified protein Rrg5. Mgm1 is a dynamin-related protein required for mitochondrial genome maintenance by mediating mitochondrial fusion [30-32]. Doc1 is involved in cyclin proteolysis as a processivity factor required for the ubiquitination activity of the anaphase promoting complex (APC) [33]. Intriguingly, Doc1 has been found in the mitochondrial proteome $[6,34]$. Thus, it is tempting to speculate that it links mtDNA replication and/or inheritance to the cell cycle. The RRG5 gene (YLRog1w) encodes a protein of unknown function. Its sequence does not show similarities to any characterized protein. As the Rrg5 protein has been localized to mitochondria $[6,34,35]$, we propose that it is a novel factor essential for maintenance of mtDNA.

In addition to class I mutants, 44 pet mutants were identified that were not complemented by mating with $\Delta$ mip 1 but could be rescued by cytoduction. These strains are able to maintain newly re-introduced mtDNA when they are grown on nonfermentable carbon sources (class IV; Additional data file 5). It is conceivable that these mutants have a tendency to spontaneously lose their mitochondrial genome when they are grown on fermentable carbon sources for longer times. This has been observed previously for $\Delta m d m_{31}$ and $\Delta m d m_{32}$ mutants that showed a pet phenotype in the screen performed by Dimmer et al. [14], but not in the screens performed by Luban et al. [17] and in the screen reported here. Freshly made $\Delta m d m_{31}$ and $\Delta m d m_{32}$ deletion mutants have been found to be able to maintain [rho+] mtDNA [36]. However, mtDNA is not stably inherited and is gradually lost after several generations of growth in glucose-containing medium [36]. To test this systematically for all class IV mutants, we replenished mtDNA by cytoduction and then passaged the strains in liquid YPD medium for 10 days to allow for loss of mtDNA. Presence or absence of mtDNA was assayed by DAPI staining immediately after cytoduction and after 10 days of replicative growth. In all strains, at least $90 \%$ of the cells contained mtDNA directly after cytoduction. Continued growth in glucose-containing medium led to increased loss of mtDNA in many mutants (Additional data file 6), suggesting that gradual loss of mtDNA accounts for the pet phenotype in many class IV mutants. Only few mutants maintained mtDNA as stably as the wild type (Additional data file 6). We consider it possible that these mutants require more generation times or special growth conditions to induce loss of mtDNA, or that these mutants rapidly accumulate mtDNA point mutations or deletions rendering the mitochondrial genome non-functional over time. Interestingly, $77 \%$ of the class IV mutants have not been found in the screens by Dimmer et al. [14] and Luban et al. [17], suggesting that many of the affected genes are only indirectly related to maintenance of respiratory activity.

\section{Genes required for protein translation in mitochondria} Next, we asked which genes are required for mitochondrial protein synthesis. Mutants defective in this process are expected to be found in either class I or class III. Class I contains mutants that have lost their mtDNA as a consequence of blocked mitochondrial translation activity, whereas class III contains mutants that are defective in translation but maintain an intact mitochondrial genome. In order to be able to test for mitochondrial protein synthesis activity, we replenished wild-type mtDNA in class I mutants by cytoduction. After this treatment, mtDNA could be visualized by DAPI staining in 102 mutants, whereas 16 mutants lacking genes 
Table 2

\section{Genes essential for maintenance of mtDNA}

\begin{tabular}{|c|c|c|}
\hline \multicolumn{3}{|c|}{ Genes encoding components involved in mtDNA metabolism } \\
\hline$* Y K L I / 4 c$ & APNI & $\begin{array}{l}\text { Involved in repair of DNA damage; located in nucleus and } \\
\text { mitochondria }\end{array}$ \\
\hline YLR304c & ACOI & $\begin{array}{l}\text { Aconitase; also independently required for mtDNA } \\
\text { maintenance }\end{array}$ \\
\hline YML06/c & PIFI & DNA helicase; active in nucleus and mitochondria \\
\hline YOL095c & HMII & Mitochondrial inner membrane localized DNA helicase \\
\hline YOR330c & MIPI & Catalytic subunit of the mitochondrial DNA polymerase \\
\hline
\end{tabular}

\begin{tabular}{|c|c|c|}
\hline \multicolumn{3}{|c|}{$\begin{array}{l}\text { Genes encoding components involved in mitochondrial } \\
\text { transcription and translation }\end{array}$} \\
\hline *YBR268w & MRPL37 & Mitochondrial ribosomal protein \\
\hline *YCRO24c & SLM5 & Mitochondrial asparaginyl-tRNA synthetase \\
\hline *YDRI75c & RSM24 & Mitochondrial ribosomal protein of the small subunit \\
\hline YHRI68w & MTG2 & $\begin{array}{l}\text { Associates with mitochondrial ribosome; possible role in } \\
\text { ribosome assembly }\end{array}$ \\
\hline$* Y K L I 69 c$ & & Dubious ORF; partially overlaps with MRPL38 \\
\hline YMR228w & MTFI & Mitochondrial RNA polymerase specificity factor \\
\hline
\end{tabular}

Genes encoding components involved in oxidative phosphorylation

*YDR079w

PETI00 Specifically facilitates the assembly of cytochrome $c$ oxidase

YPLO78C

ATP4 Subunit b of the stator stalk of mitochondrial $F_{1} F_{0}$ ATP synthase

\begin{tabular}{cll}
$\begin{array}{c}\text { Other genes } \\
* Y G L 240 w\end{array}$ & DOCI & $\begin{array}{l}\text { Required for the ubiquitination activity of the anaphase } \\
\text { promoting complex }\end{array}$ \\
$* Y L R 09 / W$ & $R R G 5$ & Unknown function \\
$Y O R 2 I I C$ & $M G M I$ & Mitochondrial GTPase involved in fusion \\
\hline
\end{tabular}

The list indicates systematic and standard names of genes essential for maintenance of newly re-introduced mtDNA in class I pet mutants. The cellular roles of the proteins are indicated according to the Saccharomyces Genome Database [19] or manually annotated. Genes that were previously not known to be essential for maintenance of mtDNA are indicated with an asterisk.

essential for maintenance of mtDNA immediately became [rho $\left.{ }^{\circ}\right]$ (see above; Table 2). For class III mutants, we reasoned that some strains might be unable to grow on medium containing glycerol as the sole carbon source because of synergistic effects of compromised mitochondrial function in combination with catabolite repression, which reduces the expression of genes required for respiration [8]. Therefore, we first relieved catabolite repression in all class III mutants by growth on glycerol-containing medium supplemented with limiting amounts of fermentable carbon source ( $3 \%$ glycerol/o.1\% glucose) before replicating the strains on glycerolcontaining medium. After this treatment, 77 strains were able to grow on plates containing glycerol as the sole carbon source (Additional data file 7). We conclude that the gene products lacking in these mutants are dispensable for respiration.

Then, we tested mitochondrial translation in a total number of 159 deletion mutants (102 class I mutants with replenished
mtDNA and 57 class III mutants unable to grow on glycerolcontaining medium after adaptation to the carbon source). Strains were grown to logarithmic growth phase in medium containing fermentable carbon sources, before cytosolic translation was stopped by the addition of cycloheximide. Newly synthesized mitochondrial proteins were labeled with $35 \mathrm{~S}$ methionine, and cell extracts were analyzed by SDS-PAGE and autoradiography.

Mitochondrial translation products could not be detected in 88 mutants (Table 3 ). We conclude that these genes are required for mitochondrial protein synthesis. Encoded proteins include 39 subunits of the mitochondrial ribosome and several additional components required for mitochondrial transcription, translation or assembly of the respiratory chain [37]. In addition, mitochondrial translation activity was absent in several mutants lacking proteins known to be required for mtDNA inheritance, such as Fzo1 [38,39], Mhr1 [40], Msh1 [41], or Mgm101 [42]. Supposedly, in these strains 
Table 3

Genes essential for mitochondrial translation

Genes encoding mitochondrial ribosomal proteins

\section{Other genes encoding known proteins}

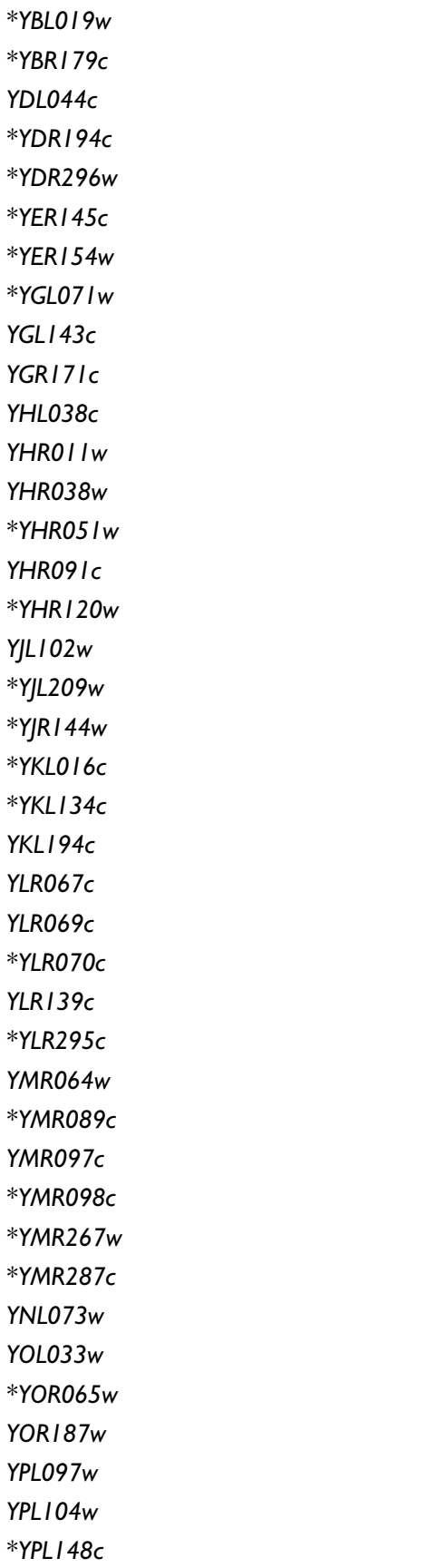

YBL090WIMRP2 I; YBRI 46WIMRPS9; YBR25 I WIMRPS5; YBR282WIMRPL27; YCR003WIMRPL32; YCR07 ICIIMG2; YDL045W-AIMRPI0; YDRI I 5W; YDR337WIMRPS28; YDR347WIMRPI; YEL050CIRML2; YER050CIRSMI8; YGLI 29CIRSM23; YGR076CIMRPL25; YGR2 I 5WIRSM27; YGR220CIMRPL9; YHRI 47CIMRPL6; YJL063CIMRPL8; YJL096WIMRPL49; YKL003CIMRPI 7; YKL I38CIMRPL3 I; YKLI 55CIRSM22; YKLI 70WIMRPL38; YKR006CIMRPLI 3; YKR085CIMRPL20; YLR3 I 2W-AIMRPLI 5; YLR439WIMRPL4; YMRI 58WI MRPS8; YMR I 88CIMRPSI 7; YMRI93WIMRPL24; YMR286WIMRPL33; YNL08ICISWS2; YNL I 77CIMRPL22; YNLI 85CIMRPLI 9; YNL252CIMRPLI 7; YNR037CIRSM I9; YORI50WIMRPL23; YORI58WIPETI 23; YPLI 73WI MRPL40

APN2

FZOI

MTF2

MSSII 6

MHRI

FTRI

OXAI

RCSI

MRFI

$M S M I$

CBP2

DIA4

RRFI

COX6

MSRI

MSHI

MEF2

CBPI

MGMIOI

ATP7

OCTI

MSTI

PET309

MEFI

XYL2

SLSI

ATPI 4

AEPI

YTA I 2

MTGI

ATP25

PPA2

DSSI

MSKI

MSEI

CYTI

TUFI

MSYI

MSDI

PPT2
Class II abasic (AP) endonuclease involved in repair of DNA damage Transmembrane GTPase required for mitochondrial fusion Mitochondrial protein involved in mRNA splicing and protein synthesis Mitochondrial RNA helicase, required for splicing of group II introns Involved in repair, recombination and maintenance of mitochondrial DNA Iron permease that mediates high-affinity iron uptake Component of the mitochondrial protein export machinery Transcription factor regulates genes involved in iron uptake and cell size Mitochondrial peptide chain release factor Met-tRNA synthetase, mitochondrial Mitochondrial splicing factor tRNA synthetase, may be involved in mitochondrial function Mitochondrial ribosome recycling factor

Cytochrome $c$ oxidase subunit VI

Arginyl-tRNA synthetase of mitochondria Involved in mitochondrial DNA repair Mitochondrial translation elongation factor Required for $C O B$ mRNA stability or 5 ' processing Mitochondrial genome maintenance protein ATP synthase subunit $d$ Mitochondrial intermediate peptidase Mitochondrial threonyl tRNA synthase Specific translational activator for the COXI mRNA Mitochondrial translation elongation factor $\mathrm{G}$ Xylitol dehydrogenase Protein involved in mitochondrial metabolism ATP synthase subunit $h$

Required for accumulation of transcript of ATP9/OLII Involved in proteolytic and chaperone activities in the inner membrane Likely functions in assembly of the large ribosomal subunit Required for the stability of ATP9 mRNA Inorganic pyrophosphatase, mitochondrial RNase, associates with the ribosome, turnover of aberrant RNAs Lysyl-tRNA synthetase, mitochondrial Glutamyl-tRNA synthetase, mitochondrial Cytochrome $c_{1}$ Translation elongation factor $\mathrm{Tu}$, mitochondrial Tyrosyl-tRNA synthetase, mitochondrial Aspartyl-tRNA synthetase, mitochondrial Activates mitochondrial acyl carrier protein 
Table 3 (Continued)

\begin{tabular}{|c|c|c|}
\hline$* Y P L 254 w$ & HFII & Component of the ADA complex \\
\hline *YPL27/w & ATPI5 & Epsilon subunit of $F_{1}-A T P$ synthase \\
\hline \multicolumn{3}{|c|}{ ORFs encoding unknown proteins } \\
\hline *YDR065w & RRGI & Unknown function, protein is detected in highly purified mitochondria \\
\hline *YDRII4c & & Dubious ORF, overlaps with YDRII5w \\
\hline *YGRI02c & & Unknown function, protein is detected in highly purified mitochondria \\
\hline$* Y G R / 50 c$ & RRG2 & Unknown function, protein is detected in highly purified mitochondria \\
\hline *YMR293c & RRG6 & Unknown function, protein is detected in highly purified mitochondria \\
\hline$* Y N L I 84 c$ & & Dubious ORF unlikely to encode a protein \\
\hline *YPRII I6w & RRG8 & Unknown function, GFP-tagged protein in mitochondria \\
\hline
\end{tabular}

The list indicates systematic and standard names of genes required for protein translation activity in class I and III pet mutants. The cellular roles of the proteins are indicated according to the Saccharomyces Genome Database (SGD) [19] or manually annotated. The list of genes has been matched to entries in SGD (biological process term: translation and cellular component term: mitochondrion). Genes that were previously not known to be required for mitochondrial translation are indicated with an asterisk.

- and likely also in other class I mutants - the mitochondrial genome had been largely lost or damaged during growth of the strains in the time between cytoduction and the labeling reaction. It should be noted that strain-dependent effects might also play a role, because, for example, $\Delta$ pet3og was observed to be completely translation-inactive here, whereas mitochondrial translation products could be observed when this mutant was constructed in the W303 genetic background [43]. Five genes (RRG1, YGR1O2c, RRG2, RRG6, and RRG8) encode uncharacterized proteins, and two dubious ORFs (YDR114c and YNL184c) overlap with genes encoding mitochondrial ribosomal proteins. A possible role of Rrg1, Rrg2, Rrg6, and Rrg8 as novel components required for mitochondrial protein synthesis is discussed below.

Specific alterations of the pattern of newly translated mitochondrial proteins were observed in ten mutants (Figure 4 and Table 4). A role in the expression of specific mitochon- dria-synthesized proteins has already been described for Aep2 [44], Cbs2 [45], Mrs1 [46], Mss51 [47], Pet54 [48,49], and Pet494 [50]. We observed that the pattern of mitochondrial translation products was also altered in $\Delta c o q 3, \Delta c y c 3$, $\Delta r r g 1 O$, and $\Delta v m a 8$ mutants. Coq3 is required for the biosynthesis of ubiquinone (coenzyme Q) in mitochondria [51]. We observed that mutant cells show a strong reduction of Cox1 (Figure 4, lane 11). Cyc3 is the mitochondrial cytochrome $c$ heme lyase that attaches the heme cofactor to apo-cytochrome $c$ in the intermembrane space [52]. Strikingly, mutant mitochondria show a strong reduction of Cox1 and cytochrome $b$ and generate an additional protein band above Cox3 (Figure 4, lane 2), pointing to a role of Cyc3 also in the biogenesis of other mitochondrial proteins. Rrg10 is an uncharacterized mitochondrial protein that might play a specific role in the expression of the mitochondrial $C O X 1$ gene (Figure 4, lane 7), as discussed below. Cox1 and Atp6 are also reduced in the $\Delta v m a 8$ mutant lacking a subunit of the vacu-

Table 4

Genes required for expression of specific mitochondrial translation products

\begin{tabular}{|c|c|c|}
\hline *YALO39c & CYC3 & Cytochrome $c$ heme lyase \\
\hline YDR/97c & CBS2 & Mitochondrial translational activator of the COB mRNA \\
\hline *YEL05 I w & VMA8 & Subunit $\mathrm{D}$ of the vacuolar $\mathrm{H}^{+}$-ATPase (V-ATPase) \\
\hline YGR222w & PET54 & $\begin{array}{l}\text { Binds to the } 5^{\prime} \text { untranslated region of the } \operatorname{COX} 3 \mathrm{mRNA} \text { to activate its translation; also binds to the COXI } \\
\text { group I intron Al5 beta to facilitate splicing }\end{array}$ \\
\hline YIR02I $w$ & MRSI & Required for the splicing of two mitochondrial group I introns \\
\hline *YJL062w-a & RRGIO & Protein of unknown function \\
\hline YLR203c & MSS5I & Required for translation of $\mathrm{COXI}$ mRNA \\
\hline YMR282c & $A E P 2$ & Likely involved in translation of the mitochondrial ATP9 mRNA \\
\hline YNR045w & PET494 & Mitochondrial translational activator specific for the COX3 mRNA \\
\hline *YOL096c & COQ3 & Component of a mitochondrial ubiquinone-synthesizing complex \\
\hline
\end{tabular}

The list indicates systematic and standard names of genes required for synthesis of only a subset of mitochondria-encoded proteins. The cellular roles of the proteins are indicated according to the Saccharomyces Genome Database [19] or manually annotated. Genes that were previously not known to be required for expression of specific mitochondrial translation products are highlighted with an asterisk. 


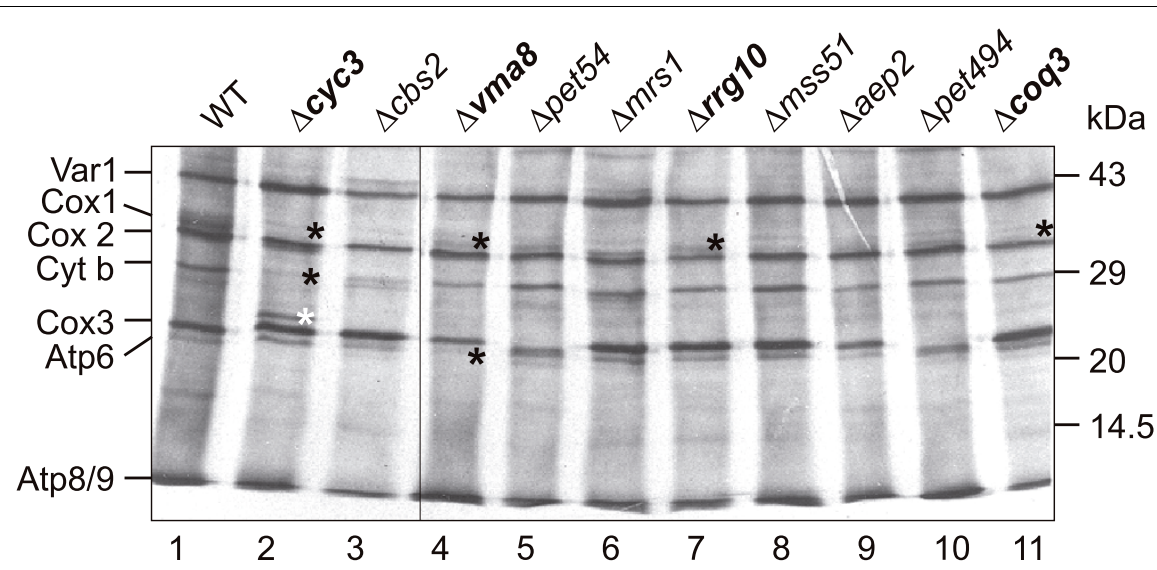

\section{Figure 4}

Mitochondrial protein synthesis in pet mutants showing an altered translation pattern. Yeast strains were grown in raffinose-containing minimal medium to logarithmic growth phase, cytosolic translation was stopped by the addition of cycloheximide, and newly synthesized mitochondrial proteins were labeled by the addition of $35 \mathrm{~S}$ methionine. After an incubation of 30 minutes at $30^{\circ} \mathrm{C}$, labeling of mitochondrial proteins was stopped by the addition of cold methionine and chloramphenicol, and cell extracts were analyzed by SDS-PAGE, transfer of proteins to nitrocellulose and autoradiography. All mutants have been analyzed in at least three independent experiments. The samples shown here have all been analyzed on the same gel (one lane has been spliced out as indicated by the thin line between lanes 3 and 4). For each strain the same amount of total cellular protein has been loaded per lane. Mutants that were previously not known to be affected in the synthesis of specific mitochondria-encoded proteins are in bold letters. Alterations of the translation pattern mentioned in the text are marked with asterisks. Black asterisks mark bands that are absent, and the white asterisk marks an additional band present in $\Delta$ cyc3. WT, wild type.

olar $\mathrm{H}^{+}$ATPase [53], suggesting that expression of these proteins is particularly sensitive to changes in cell metabolism (Figure 4, lane 4).

\section{Other genes important for respiration}

In sum, 61 respiratory-deficient mutants showed a wild-typelike mitochondrial translation pattern (Additional data file 8). We conclude that these genes are not essential for mitochondrial genome maintenance or mitochondrial protein synthesis. This group contains 32 genes encoding known mitochondrial proteins, many of which are required for assembly of the respiratory chain. Eighteen genes encode known extra-mitochondrial proteins, and 11 ORFs are uncharacterized. Five of the uncharacterized ORFs are unlikely to encode proteins because they overlap with known protein-coding genes, whereas six ORFs (YDL129w, $Y D L 133 w, Y D L O 33 w / R R G 4, Y N L 213 c / R R G 9, Y O L O 71 w$, and YOLO83w) might encode novel proteins involved in maintenance of respiratory activity. Possible roles of Rrg4 and Rrg9 in this process are discussed below.

Half of the pet genes encoding extra-mitochondrial proteins are associated with vacuolar functions (Additional data file 8). Moreover, a surprisingly large number of genes encoding V-ATPase subunits are highly penetrant pet genes (Figure 1c; Additional data file 3). What might be the function of the vacuole in maintenance of respiratory activity in yeast? We suggest three possibilities. First, vacuolar functions in metabolite storage or in cytosolic ion and $\mathrm{pH}$ homeostasis $[54,55]$ might interfere with mitochondrial metabolism. Second, loss of V-
ATPase activity has been reported to render cells hypersensitive to oxidative stress [56-58], which might have an impact on mitochondrial functions as well. And third, the vacuole is the terminal compartment receiving cellular components destined for degradation by autophagic pathways. As also mitochondria are degraded by autophagy in yeast [59], it is possible that the vacuole plays an important role in mitochondrial quality control and turn-over. The high number of pet mutants lacking V-ATPase subunits clearly demonstrates that there is an important - as yet not fully understood - functional relationship between the vacuole and mitochondria.

\section{Contribution of acquired defects to maintenance of respiratory activity}

The respiratory-deficient phenotype of 23 pet mutants was rescued by mating with $\Delta$ mip 1 as well as by cytoduction (class II; Additional data file 9). These mutants contained a $\left[\mathrm{rho}^{+}\right]$ mitochondrial genome, as indicated by the mating experiment. In addition, three independently performed cytoduction experiments suggest that replenishment of cytoplasmic material reproducibly restores and maintains respiratory growth, at least for a few generations. These observations point to the possibility that respiratory competence may involve acquired properties that are not strictly linked to the nuclear or mitochondrial genotype. In order to corroborate this assumption, we tested whether cytoduction with a [rho $]$ donor strain would also restore respiratory growth. Rescue was observed in 11 strains (Additional data file 9), suggesting that, at least in some cases, cytoplasmic components other than mtDNA are able to improve respiratory functions. We 
hypothesize that respiratory deficiency may be an acquired phenotype that does not exclusively depend on the genotype.

Among ten class II mutants lacking known mitochondrial proteins $(\Delta \operatorname{coq} 5, \Delta \operatorname{coq} 10, \Delta \operatorname{cox} 10, \Delta \operatorname{cox} 16, \Delta \operatorname{cox} 19, \Delta m c t 1$, $\Delta m s s 2, \Delta n f u 1, \Delta \operatorname{slm}_{3}$, and $\Delta$ som1) are four mutants that are specifically defective in the assembly of the cytochrome $c$ oxidase (COX complex). Cox10 is required for the synthesis of the heme A cofactor [60,61], Cox19 is a metallochaperone that delivers copper to the COX complex [62], Mss2 is required for the membrane translocation of the carboxyl terminus of the mitochondria-encoded Cox2 protein [63], and Cox16 contributes to assembly of the COX complex by an as yet unknown mechanism [64]. Intriguingly, all four of these proteins are required for assembly of COX subunits at a post-translational stage. While respiratory-deficiency in $\Delta \operatorname{cox} 10, \Delta \operatorname{cox} 16$, $\Delta c o x 19$, and $\Delta m s s 2$ mutants has been documented before [6o,62-64], we asked whether acquired properties might contribute to the loss of respiratory activity in these mutants. To exclude effects due to differences in mtDNA copy number, we first quantified the abundance of the mitochondrial $\mathrm{COX}_{3}$ gene by RT-PCR. We found that mtDNA is stably maintained in $\Delta \operatorname{cox} 10, \Delta \operatorname{cox} 16, \Delta \operatorname{cox} 19$, and $\Delta m s s 2$ mutants at a level very similar to wild-type cells (Figure $5 \mathrm{a}$ ).

Next, we tried to rescue the deletion mutants with plasmids encoding wild-type copies of the respective genes under control of their endogenous promoters. Remarkably, after growth on selective medium a substantial number of transformants remained respiratory-defective after complementation with the respective wild-type gene (Figure 5b). The occurrence of respiratory-deficient clones was not induced by the transformation procedure per se because transformation of wild-type cells with the same plasmids yielded 100\% respiration-competent clones (not shown). In order to test whether $\Delta \operatorname{cox} 10, \Delta \operatorname{cox} 16, \Delta \operatorname{cox} 19$, and $\Delta m s s 2$ clones lose properties required for respiratory competence over time, we subjected the deletion mutants to chronological aging [65], that is, continued incubation of stationary phase cultures. Mutant cells were incubated on glucose-containing medium for several days at room temperature before transformation with the complementing plasmids. Under these conditions, the fraction of clones that could not be rescued increased to 60 to $81 \%$ for mutant cells, whereas only $6 \%$ of aged wild-type clones were observed to be respiratory-deficient after transformation (Figure $5 \mathrm{~b}$ ). This suggests that mitochondria in $\Delta$ coxio, $\Delta$ cox16, $\Delta$ cox19, and $\Delta m s s 2$ cells become irreversibly damaged over time, producing a respiratory-deficient phenotype that cannot be rescued any more. Apparently, this damage is already induced during vegetative growth and is markedly enhanced during aging.

As mitochondrial metabolism and aging are linked to the generation of potentially harmful reactive oxygen species (ROS) [66] we asked whether ROS accumulate in COX assembly mutants. High levels of ROS generated in yeast cells convert the non-fluorescent compound dihydrorhodamine 123 (DHR) to the oxidized fluorescent chromophore rhodamine 123 [67]. Upon incubation of young wild-type $\Delta \operatorname{cox} 10, \Delta \operatorname{cox} 16$, $\Delta$ cox19, and $\Delta m s s 2$ cultures with DHR ( $8 \mathrm{~h}$ in liquid YPD medium) only very few cells showed significant staining (Figure $5 \mathrm{c}$ ). After continued incubation ( $32 \mathrm{~h}$ ), about $60 \%$ of wildtype cells and 90 to $98 \%$ of mutant cells showed significant rhodamine staining (Figure $5 \mathrm{c}$ ). Very similar results were obtained when aging was allowed for up to $80 \mathrm{~h}$ (not shown). Furthermore, we noticed that rhodamine staining in wildtype cells was relatively faint and often restricted to tubular structures (presumably representing the mitochondrial network), whereas the signal was much stronger and dispersed throughout the cytosol in mutant cells (Figure $5 \mathrm{c}$ ). We conclude that $\Delta \operatorname{cox} 10, \Delta \operatorname{cox} 16, \Delta \operatorname{cox} 19$, and $\Delta m s s 2$ cells produce elevated ROS levels during chronological aging. Presumably, ROS induce irreversible damage to mitochondrial proteins, lipids and/or mtDNA, thereby preventing rescue of the mutant phenotype by transformation with complementing plasmids. On the other hand, replenishment of fresh mitochondria by cytoduction might improve respiratory performance, at least for a limited time. It remains to be shown whether accumulation of ROS-induced damage is a general feature of class II mutants.

\section{Novel components essential for respiratory growth}

All previously uncharacterized $R R G$ genes analyzed herein can be clearly related to mitochondrial functions. Proteins Rrg1, Rrg2, and Rrg5 through Rrg10 have been localized to mitochondria by high-throughput green fluorescent protein (GFP) fusion protein localization [35] and/or mitochondrial proteome analysis $[6,34]$. The Rrg3 protein carries a putative mitochondrial presequence, whereas the intracellular location of Rrg4 remains unknown. Functional properties of $R R G$ genes are summarized in Table 5 .

$\Delta r r g 1, \Delta r r g 2, \Delta r r g 4, \Delta r r g 5, \Delta r r g 6, \Delta r r g 8$, and $\Delta r r g 9$ are class I pet mutants lacking a functional mitochondrial genome. DAPI staining revealed defects in the organization of mtDNA that emerged early after introduction of wild-type mitochondrial genomes by cytoduction in $\Delta r r g 1, \Delta r r g 2$, $\Delta r r g 6, \Delta r r g 8$, and $\Delta r r g 9$ mutants. Nucleoids appeared larger compared to the wild type, the number of nucleoids per cell was reduced, and several cells were completely devoid of mtDNA (not shown). These observations suggest that Rrg1, Rrg2, Rrg6, Rrg8, and Rrg9 play an important role in maintenance of mtDNA. Immediate and complete loss of mtDNA after cytoduction in the $\Delta r r g 5$ mutant indicates an essential role of $\operatorname{Rrg} 5$ for maintenance of mtDNA (see above).

Interestingly, Rrg2 contains a pentatricopeptide (PPR) motif. PPR protein-encoding genes can be found in virtually all sequenced eukaryotic genomes, but are particularly abundant in plants. PPR proteins are localized in plastids and mitochondria where they are involved in the control of various stages of gene expression [68]. Lack of mitochondrial transla- 


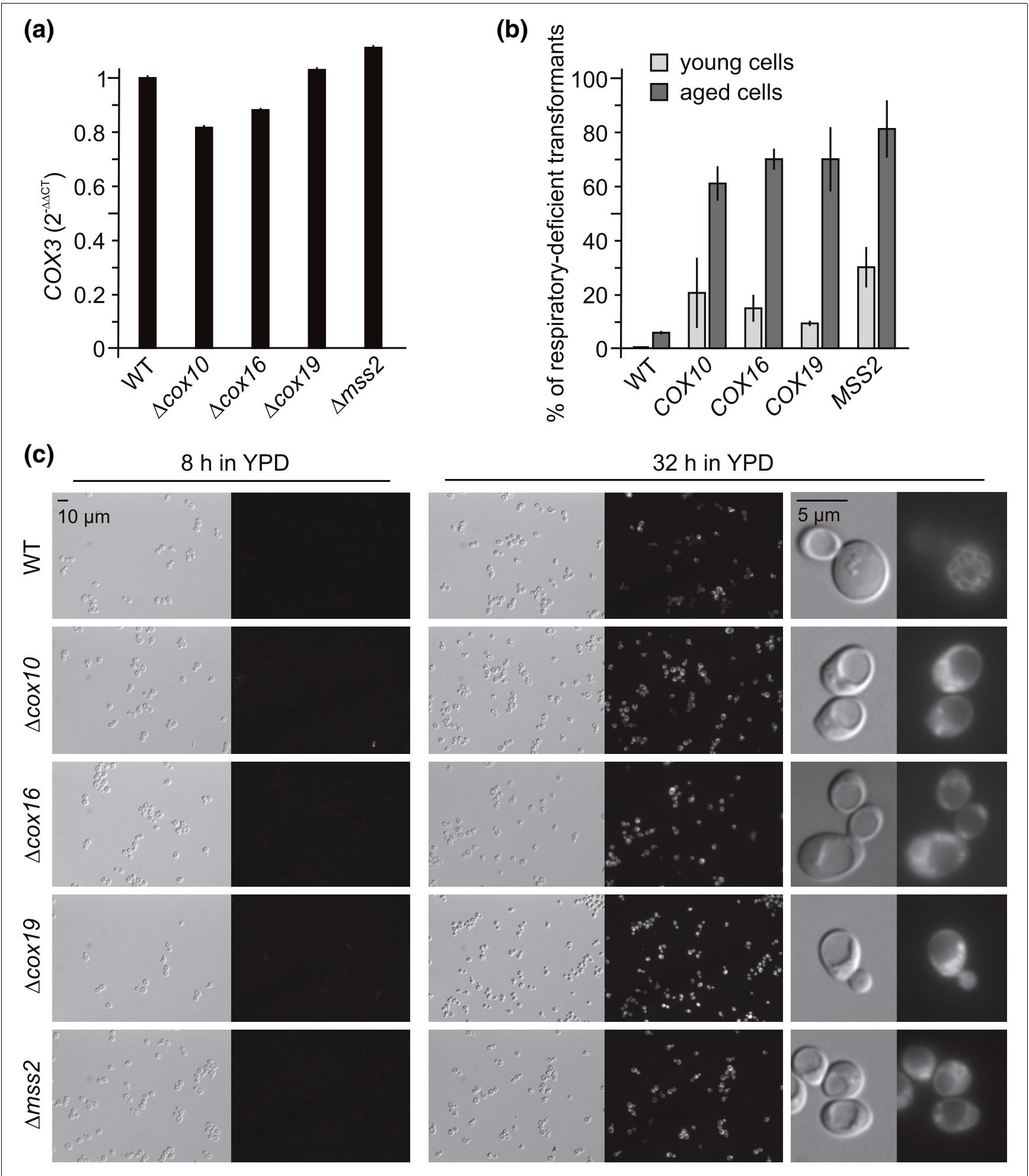

Figure 5 (see legend on next page) 
Figure 5 (see previous page)

Acquired phenotypes of COX assembly mutants. (a) Quantification of mtDNA. Yeast strains were grown overnight in liquid glucose-containing medium. Total DNA was isolated and the copy number of the mitochondrial COX3 gene was related to that of the nuclear GAL4 gene by RT-PCR and calculation of the $2^{-\Delta \Delta C}$ value. Error bars indicate standard deviations of triplicate PCR reactions. (b) Complementation test. $\Delta$ cox $10, \Delta$ cox I6, $\Delta$ cox I 9 , and $\Delta m s s 2$ strains taken from the MAT $\alpha$ yeast deletion library have been transformed with single copy plasmids carrying the respective complementing wild-type alleles under control of their endogenous promoters. Wild-type cells (WT) were transformed with an empty vector. Young cells were grown on complete medium at $30^{\circ} \mathrm{C}$ overnight before transformation (light bars). Aged cells were incubated on complete medium at room temperature for 14 to 28 days before they were transferred to fresh plates, grown at $30^{\circ} \mathrm{C}$ overnight, and transformed with complementing plasmids (dark bars). Three days after transformation, colonies were replicated on plates containing fermentable or non-fermentable carbon sources, and the percentage of respiratory-deficient transformants was determined. Error bars indicate standard deviations of three independent experiments. (c) ROS accumulation. Yeast strains were grown for the indicated time periods in liquid glucose-containing medium (YPD), stained by the addition of DHR and analyzed by differential interference microscopy (left panels) and fluorescence microscopy (right panels). All fluorescent micrographs were taken with identical camera settings.

tion activity and early loss of mtDNA observed here are consistent with a role of Rrg2 in control of mitochondrial gene expression.

${ }^{\Delta r r g 3}$ is a class III pet mutant able to maintain a $\left[r h o^{+}\right]$ genome and wild-type-like mitochondrial protein translation activity. Although a mitochondrial location of Rrg3 has not been shown experimentally, the Mitoprot program [69] predicts the presence of a mitochondrial presequence with a high probability (0.9484). Mutants lacking Rrg3 (alternative name Aim22) show an increased petite frequency [70]. The protein has high homology to lipoate-protein ligase A family members [71]. Thus, it is conceivable that $\operatorname{Rrg} 3$ mediates the attachment of the lipoic acid cofactor to mitochondrial multienzyme complexes, such as pyruvate dehydrogenase, $\alpha$ ketoglutarate dehydrogenase, glycine decarboxylase or others. Intriguingly, it has recently been reported that lipoateprotein ligase activity is important for maturation of RNase $\mathrm{P}$, an enzyme that processes mitochondrial precursor tRNAs [72]. It will be interesting to determine whether Rrg3 plays a specific role in this process.
The $\Delta r r g 4$ mutant has recently been identified as one of 86 gene deletion mutants that show an increased assembly of Rad52, a central protein of the homologous recombination machinery, in subnuclear foci reflecting DNA repair centers. Therefore, the gene has been named IRC19 (for 'increased recombination centers') [73]. Interestingly, several other genes related to mitochondrial function were also isolated in this screen, including CBT1, COX16, MRP17, MRPL1, $M R P S 16$, and $Y M R 31$. It has been suggested that an increase of oxidative damage due to impaired respiratory chain functions might stimulate spontaneous DNA lesions in the nucleus and, therefore, constitutes a functional link between mitochondrial respiration and DNA repair processes in the nucleus [73]. As a Rrg4-GFP fusion protein can not be visualized in cells [35], the intracellular location of $\operatorname{Rrg} 4$ remains unknown.

The RRG6 gene has recently been found in a screen for components involved in remodelling of the endoplasmic reticulum (ER). It has been named HER2 (Hmg2-induced ER remodelling); however, its molecular role in shaping the ER membrane remained unknown [74]. As the Rrg6 protein has been localized to mitochondria by both GFP tagging and pro-

Table 5

\begin{tabular}{|c|c|c|c|c|c|c|}
\hline & Systematic name & $\begin{array}{l}\text { Mitochondrial } \\
\text { localization }\end{array}$ & $\Delta$ mipl mating & Cytoduction & $\begin{array}{l}\text { Nucleoids after } \\
\text { cytoduction }\end{array}$ & $\begin{array}{l}\text { Translation activity } \\
\text { after cytoduction }\end{array}$ \\
\hline RRGI & YDR065w & {$[34]$} & - & - & Altered & Absent \\
\hline RRG2 & YGRI50c & {$[34,35]$} & - & - & Altered & Absent \\
\hline RRG3 (AIM22) & YJL046w & [69] & + & - & WT & WT \\
\hline RRG4 (IRCI9) & YLL033w & Unknown & - & - & WT & WT \\
\hline RRG5 (GEP5) & YLR09/w & {$[6,34,35]$} & - & - & Absent & Absent \\
\hline RRG6 (HER2) & YMR293c & {$[6,34,35]$} & - & - & Altered & Absent \\
\hline RRG7 & YOR305w & {$[35]$} & + & + & ND & ND \\
\hline RRG8 & YPRII6w & {$[35]$} & - & - & Altered & Absent \\
\hline RRG9 & $Y N L 2 I 3 c$ & [34] & - & - & Altered & WT \\
\hline RRG IO & YJL062w-a & {$[34,35]$} & + & - & WT & Altered \\
\hline
\end{tabular}

References refer to published evidence of mitochondrial localization of Rrg proteins; + indicates rescue by mating with $\Delta$ mip / or cytoduction, respectively. WT, wild type-like; ND, not determined. See text for details. 
teome analysis $[6,34,35]$, we propose that its primary function is related to maintenance of respiratory activity. The protein is highly homologous to bacterial glutamyl-tRNA amidotransferases, and a role in mitochondrial protein synthesis is consistent with our observation that mitochondrial translation is blocked in the $\Delta$ rrg6 mutant (Table 3). Recently, $R R G 5$ (alternative name GEP5) and RRG6 (alternative names GEP6 or HER2) have been shown to genetically interact with genes encoding prohibitin ring complexes in the mitochondrial inner membrane [75]; however, the functional significance of this interaction is not yet understood.

$\Delta r r g 7$ is a class II pet mutant presumably acquiring respiratory deficiency independent of its genotype. The $R R G 7$ gene encodes a mitochondrial protein [35] that has homologs in fungi and other lower eukaryotes. Its function in mitochondrial biogenesis is currently unknown; however, the deletion mutant has been reported to exhibit increased sensitivity to the synthetic tripeptide arsenical 4-(N-(S-glutathionylacetyl)amino) phenylarsenoxide that targets mitochondria by inactivating the adenine nucleotide translocator. This drug inhibits proliferation of actively dividing endothelial cells and is an inhibitor of angiogenesis during tumor formation [76].

$\Delta r r g 1 O$ is a class III pet mutant able to maintain a $\left[r h o^{+}\right]$ genome. The RRG1O gene encodes a small mitochondrial protein [34,35] of only 85 amino acid residues. Analysis of the mitochondrial translation pattern revealed a reduction of Cox1, suggesting that Rrg10 plays a specific role in transcription or maturation of mitochondrial mRNAs and/or translation or assembly of mitochondrial gene products.

\section{Conclusions}

Surprisingly, only a limited number of mutants reproducibly show a pet phenotype when different versions of the yeast deletion library are screened for growth on non-fermentable carbon sources. While some differences can be ascribed to wrong deletions present in the library, most of the variations are likely due to intrinsic properties of the mutant strains. We present four lines of evidence suggesting that the plasticity of pet phenotypes is much greater than previously anticipated. First, several deletions produce different phenotypes in different versions of the deletion library (Figure 1a, b; Additional data file 3); second, a number of mutants lose mtDNA at a high rate upon continued incubation in glucose-containing medium (Additional data file 6); third, respiratory deficiency can be reversed by relief of catabolite repression in a relatively large number of mutants (Additional data file 7); and fourth, several $\left[\mathrm{rho}^{+}\right]$pet mutants accumulate irreversible damage resulting in an improvement of respiratory performance after cytoduction (Figure 5; Additional data file 9). It is a challenge for the future to examine further contributions of environmental factors, nutrient supply, and possible epigenetic mechanisms to phenotypic plasticity.
Comparative gene deletion analysis enabled us to define by stringent criteria a set of 163 protein-coding genes (13 dubious ORFs subtracted from the 176 mutants found in all pet screens of the library) that are obligatorily required for respiratory metabolism in yeast. These include ten largely uncharacterized genes, $R R G 1$ through $R R G 1 O$. Remarkably, almost all of these highly penetrant mutants (95\%) have been reported to show decreased fitness on non-fermentable carbon sources when the whole-genome pool of yeast deletion mutants was analyzed [77,78]. While the approach pursued by Steinmetz et al. [77] resulted in a relatively large set of genes potentially required for respiratory growth (466 genes, $43.1 \%$ of which encode mitochondrial proteins), the comparative gene deletion approach pursued here apparently is more selective (176 genes, $73.3 \%$ of which encode mitochondrial proteins). A high resolution of our comparative gene deletion analysis is also apparent from a comparison with the results we obtained after our first screen of the deletion library reported in the Dimmer et al. study [14], which yielded 341 pet genes (only $54.8 \%$ of which encode mitochondrial proteins). Our present work suggests that 165 of these originally identified mutants do not reproducibly give rise to a pet phenotype and should be considered as important but not essential for respiratory growth of yeast. Thus, Figure 1c gives a significantly improved representation of cellular functions of genes essential for respiration. A recent study by Hess et al. [70] reports a computational prediction of 193 candidate genes and subsequent analysis of their possible roles in mitochondrial biogenesis. They found that $\Delta r r g 2$ and $\Delta r r g 6$ mutants are respiratory deficient, and that the $\Delta r r g 3$ mutant shows an increased petite frequency [70]. However, the remaining seven $R R G$ genes were only found by the comparative gene deletion analysis described here, demonstrating the value of our approach.

The systematic functional analysis of pet mutants reported here uncovered roles of 8 novel components in mtDNA maintenance, 30 novel components in mitochondrial protein synthesis, and 4 novel components in expression of specific mitochondrial translation products. We suggest that these data may serve as positive lists for genes important for respiratory growth, mtDNA maintenance and mitochondrial protein synthesis. It should be pointed out that components might have been missed that are encoded by redundant genes or that are not correct in the deletion library. Furthermore, some genes might be specifically required only under certain growth conditions or in certain genetic backgrounds. While a mechanistic understanding of the molecular processes contributing to respiratory activity will require further rigorous experimentation, the systematic large-scale functional analysis of pet mutants reported here is a first step towards a definition of the complements of genes required for maintenance of the mitochondrial genome and mitochondrial protein translation. Together with integrated analyses of different genomic and proteomic approaches [78], combination of computational approaches with quantitative experimentation 
[70], and the construction of protein interaction networks [79] it will contribute to an understanding of the systems properties of mitochondria with steadily increasing resolution.

\section{Materials and methods Yeast strains and plasmids}

Yeast strains used in this study were isogenic to BY4741, BY4742 and BY4743 [18], with the exception of strain J1361 [8o], which was used for cytoduction. The $\left[\mathrm{rho}^{\circ}\right]$ cytoduction donor strain was generated by growth of J1361 overnight in YPD medium supplemented with $50 \mu \mathrm{g} / \mathrm{ml}$ ethidium bromide. Complete loss of mtDNA was controlled by DAPI staining. The MAT $\alpha$ gene deletion library [16] and its supplement covering newly assigned small ORFs [21] was obtained from BioCat (Heidelberg, Germany), and MATa single mutant $\triangle$ mip1 was obtained from EUROSCARF (Frankfurt, Germany). Plasmid pRS416/MSS2 was constructed by PCR amplification of the $M S S 2$ gene using primers 5 AAA GGA TCC GAT TTT ATG TGT GGA ATG CTA ACG ATG AAC and 5' AAA CTC GAG CTC TAA CAG TAT TTC CTA ATT ATT TCA TAG GTA AC and subcloning into the BamHI and XhoI sites of vector pRS416 [81]. Plasmid pRS416/COX16 was constructed by PCR amplification of the $C O X 16$ gene using primers 5' AAA GGA TCC AAT ATT ACC GTG AAT ATC GCG AGC TAC and 5' AAA CTC GAG AGG TAT TTA CAA TCA TTT CCT AGA CAT TCT and subcloning into the BamHI and XhoI sites of vector pRS416. For complementation tests, yeast strains were transformed with plasmids $\mathrm{pG}_{12} / \mathrm{T} 4$ [6o] expressing COX1O, pRS416/COX16, pG188/T1 [62] expressing COX19, or pRS416/MSS2.

PCR analyses to confirm the identity of deletion mutants were performed in a way that one primer was homologous to a sequence within the coding region or within the deletion marker cassette, respectively, whereas the other primer was homologous to a sequence outside the deleted part of the gene. Thus, a PCR product can be generated only if the correct allele corresponding to the primer combination is present. Primers used to confirm the identity of yeast deletion mutants are listed in Additional data file 10.

\section{Yeast genetic methods}

$S$. cerevisiae was cultivated and manipulated according to standard procedures [82]. For screening for respiratory-deficient mutants, yeast deletion strains were manually transferred with a sterile pinning tool from 96-well plates to rich media plates with either $2 \%$ glucose as fermentable (YPD) or $3 \%$ glycerol as non-fermentable (YPG) carbon source. The screening of the entire library on YPG was performed once. The screening procedure was as similar as possible to the screen performed earlier by us in the Dimmer et al. study [14]. Respiratory-deficient mutants were screened in addition on media containing $3 \%$ ethanol or $3 \%$ lactate ( $\mathrm{pH}$ adjusted to 7.0 with $\mathrm{NaOH}$ ) as non-fermentable carbon sources. The growth behavior was evaluated by visual inspection after 3 days (YPD) or 6 days (YPG and other non-fermentable media) of incubation at $30^{\circ} \mathrm{C}$.

For high-throughput complementation tests with $\Delta$ mip1, yeast deletion strains were transferred with a sterile pinning tool from 96-well plates to a lawn of MATa $\triangle$ mip1 cells on YPD plates. After incubation overnight to allow for mating, cells were replica-plated two times on plates containing minimal SD medium selective for diploid cells. Then, growth on YPG plates was determined as above. Cytoduction was performed as described [80]. Cytoduction experiments were repeated at least three times. To adapt yeast deletion strains to non-fermentable carbon sources, cells were transferred from YPD plates to YPG plates containing $0.1 \%$ glucose, replica-plated once on YPG/o.1\% glucose and then replica-plated on YPG.

\section{Analysis of mitochondrial translation products}

Labeling of mitochondrial translation products in vivo was performed essentially as described [83] with the following minor modifications: cytosolic translation was stopped with $0.3 \mathrm{mg} / \mathrm{ml}$ cycloheximide, the labeling reaction was performed for 30 minutes, and the chase reaction was performed for 15 minutes. Mitochondrial translation products were analyzed by SDS-PAGE, transfer to nitrocellulose and autoradiography.

\section{Assay of accumulation of irreversible damage during chronological aging}

Using sterile toothpicks, cells were taken from glycerol stocks and spread on YPD plates as patches of about $2 \mathrm{~cm}^{2}$ size. Plates were incubated for 14 to 28 days at room temperature to allow chronological aging. Then, a small amount of aged cells (or young cells taken directly from glycerol stocks as a control) was spread on a fresh YPD plate, incubated overnight at $30^{\circ} \mathrm{C}$, and transformed according to the rapid transformation protocol described by Truong and Gietz [84]. Using sterile toothpicks, at least 100 transformants were transferred as short streaks (approximately $1 \mathrm{~cm}$ ) to fresh SD plates selective for the marker of the transformed plasmids. Plates were incubated for 1 day at $30^{\circ} \mathrm{C}$ and then replica-plated on YPD and YPG using sterile velvet. Carbon source-dependent growth of transformants was visually scored after 2 to 3 days at $30^{\circ} \mathrm{C}$.

\section{Staining of mtDNA, DHR staining and microscopy}

Staining of mtDNA with DAPI in methanol-fixed cells was as described [30]. For the analysis of ROS production, $1 \mu \mathrm{DHR}$ $(2.5 \mathrm{mg} / \mathrm{ml}$ in DMSO) was added to $500 \mu \mathrm{l}$ cell suspension and incubated for $2 \mathrm{~h}$ at $30^{\circ} \mathrm{C}$. Cells were harvested by centrifugation, washed in phosphate-buffered saline, resuspended in phosphate-buffered saline and analyzed by microscopy. Epifluorescence microscopy was performed using a Zeiss Axioplan 2 microscope equipped with a HBO 100 mercury lamp, Zeiss filter sets 01 and 09 and a Plan-Neofluar 100 $\times 1.30$ NA Ph3 oil objective (Carl Zeiss Lichtmikroskopie, Göttingen, 
Germany). Images were recorded with an Evolution VF Mono Cooled monochrome camera (Intas, Göttingen, Germany) and processed with Image Pro Plus 5.0 and Scope Pro 4.5 software (MediaCybernetics, Silver Springs, MD, USA).

\section{RT-PCR}

Yeast strains were grown overnight in liquid YPD medium and DNA was extracted using the YeaStar ${ }^{\mathrm{TM}}$ Genomic DNA Kit (Zymo Research, Orange, USA) according to the manufacturer's instructions. PCR reactions were performed in $20 \mu \mathrm{l}$ volume in 96-well plates using Maxima ${ }^{\mathrm{TM}}$ SYBR Green qPCR Master Mix (2×) (Fermentas, St Leon-Rot, Germany) according to the manufacturer's instructions in an ABI PRISM 7000 Sequence Detection System (Applied Biosystems, Foster City, CA, USA). The following primers were used: GAL4 forward, 5' TTT CTC CTG GCT CAG TAG GGC; GAL4 reverse, 5' AGT TAC GAG AGG GTG GAC GGT; $\mathrm{COX}_{3}$ forward, 5' ATT GAA GCT GTA CAA CCT ACC GAA TT; $C O X_{3}$ reverse, 5' CCT GCG ATT AAG GCA TGA TGA. Data were analyzed with Sequence Detection Software Version 1.2.3 7000 System SDS software Core Application (Applied Biosystems) and calculated according to the $2^{-\Delta \Delta C} \mathrm{~T}^{-\operatorname{method}}$ [85].

\section{Abbreviations}

COX: cytochrome $c$ oxidase; DAPI: 4',6-diamidino-2-phenylindole; DHR: dihydrorhodamine 123; ER: endoplasmic reticulum; GFP: green fluorescent protein; mtDNA: mitochondrial DNA; ORF: open reading frame; PPR: pentatricopeptide; ROS: reactive oxygen species.

\section{Authors' contributions}

SM performed the experiments, SM and BW conceived the study, analyzed the data and wrote the manuscript.

\section{Additional data files}

The following additional data are available with the online version of this paper: a table listing pet genes isolated from the MATa deletion library (Additional data file 1); a table listing pet genes unique to this study (Additional data file 2); a table listing pet genes grouped according to their occurrence in pet screens and localization and function of the encoded gene products (Additional data file 3); a table listing pet genes producing growth defects only on specific carbon sources (Additional data file 4); a table listing mutants belonging to four classes of pet genes (Additional data file 5); a table showing quantification of loss of mtDNA in class IV pet mutants (Additional data file 6); a table listing pet genes dispensable for respiration (Additional data file 7); a table listing genes required for respiratory activity in class I and III pet mutants that show a wild-type pattern of mitochondrial translation products (Additional data file 8); a table listing genes possibly affecting mitochondrial function in combination with acquired defects (Additional data file 9); a table listing prim- ers used to confirm the identity of yeast deletion mutants (Additional data file 10).

\section{Acknowledgements}

This work was supported by the Deutsche Forschungsgemeinschaft. We thank Robert JD Reid for making yeast strain JI36I available to us, Alexander Tzagoloff for plasmids pG I 2/T4 and pG 188/TI, Alexander Kastaniotis and Johannes Herrmann for helpful discussions, and Melanie Krist for her contributions to some experiments.

\section{References}

I. Saraste M: Oxidative phosphorylation at the fin de siècle. Science 1999, 283: | 488- I493.

2. Lane N: Power, Sex, Suicide. Mitochondria and the Meaning of Life Oxford, UK: Oxford University Pressa; 2005.

3. de Vries S, Van Witzenburg R, Grivell LA, Marres CA: Primary structure and import pathway of the rotenone-insensitive NADH-ubiquinone oxidoreductase of mitochondria from Saccharomyces cerevisiae. Eur J Biochem 1992, 203:587-592.

4. Marres CA, de Vries S, Grivell LA: Isolation and inactivation of the nuclear gene encoding the rotenone-insensitive internal NADH: ubiquinone oxidoreductase of mitochondria from Saccharomyces cerevisiae. Eur J Biochem I99I, 195:857-862.

5. Gray MW, Burger G, Lang BF: Mitochondrial evolution. Science 1999, 283:|476-148I.

6. Sickmann A, Reinders J, Wagner $Y$, Joppich C, Zahedi R, Meyer HE, Schönfisch B, Perschil I, Chacinska A, Guiard B, Rehling P, Pfanner N, Meisinger C: The proteome of Saccharomyces cerevisiae mitochondria. Proc Natl Acad Sci USA 2003, 100:13207-I32I 2.

7. Grivell LA, Artal-Sanz M, Hakkaart G, de Jong L, Nijtmans LG, van Oosterum K, Siep M, Spek $\mathrm{H}$ van der: Mitochondrial assembly in yeast. FEBS Lett 1999, 452:57-60.

8. Gancedo JM: Yeast carbon catabolite repression. Microbiol Mol Biol Rev 1998, 62:334-36I.

9. Piskur J, Rozpedowska E, Polakova S, Merico A, Compagno C: How did Saccharomyces evolve to become a good brewer? Trends Genet 2006, 22: 183-186.

10. Johnston M: Feasting, fasting and fermenting. Glucose sensing in yeast and other cells. Trends Genet 1999, 15:29-33.

II. Ephrussi B, Hottinguer H, Tavlitzki J: Action de l'acriflavine sur les levures II. Étude génétique du mutant "petite colonie". Ann Inst Pasteur 1949, 76:419-442.

12. Tzagoloff A, Dieckmann CL: PET genes of Saccharomyces cerevisiae. Microbiol Rev 1990, 54:21 I-225.

13. Contamine V, Picard M: Maintenance and integrity of the mitochondrial genome: a plethora of nuclear genes in the budding yeast. Microbiol Mol Biol Rev 2000, 64:28I-3I5.

14. Dimmer KS, Fritz S, Fuchs F, Messerschmitt M, Weinbach N, Neupert W, Westermann B: Genetic basis of mitochondrial function and morphology in Saccharomyces cerevisiae. Mol Biol Cell 2002, 13:847-853.

15. Bolotin-Fukuhara M, Grivell LA: Genetic approaches to the study of mitochondrial biogenesis in yeast. Antonie Van Leeuwenhoek 1992, 62:131-153.

16. Giaever G, Chu AM, Ni L, Connelly C, Riles L, Veronneau S, Dow S, Lucau-Danila A, Anderson K, Andre B, Arkin AP, Astromoff A, Bakkoury ME, Bangham R, Benito R, Brachat S, Campanaro S, Curtiss M, Davis K, Deutschbauer A, Entian KD, Flaherty P, Foury F, Garfinkel DJ, Gerstein M, Gotte D, Güldener U, Hegemann JH, Hempel S, Herman Z, et al.: Functional profiling of the Saccharomyces cerevisiae genome. Nature 2002, 418:387-391.

17. Luban C, Beutel M, Stahl U, Schmidt U: Systematic screening of nuclear encoded proteins involved in the splicing metabolism of group II introns in yeast mitochondria. Gene 2005, 354:72-79.

18. Brachmann CB, Davies A, Cost GJ, Caputo E, Li J, Hieter P, Boeke JD: Designer deletion strains derived from Saccharomyces cerevisiae S288C: a useful set of strains and plasmids for PCRmediated gene disruption and other applications. Yeast 1998 , 14:115-132.

19. Issel-Tarver L, Christie KR, Dolinski K, Andrada R, Balakrishnan R, Ball CA, Binkley G, Dong S, Dwight SS, Fisk DG, Harris M, Schroeder M, Sethuraman A, Tse K, Weng S, Botstein D, Cherry JM: Saccharo- 
myces Genome Database. Methods Enzymol 2002, 350:329-346.

20. Wysocki R, Roganti T, Van Dyck E, de Kerchove D'Exaerde A, Foury $F$ : Disruption and basic phenotypic analysis of 18 novel genes from the yeast Saccharomyces cerevisiae. Yeast 1999, 15:165-17|.

21. Kastenmayer JP, Ni L, Chu A, Kitchen LE, Au WC, Yang H, Carter CD, Wheeler D, Davis RW, Boeke JD, Snyder MA, Basrai MA: Functional genomics of genes with small open reading frames (sORFs) in S. cerevisiae. Genome Res 2006, 16:365-373.

22. Foury F: Cloning and sequencing of the nuclear gene MIPI encoding the catalytic subunit of the yeast mitochondrial DNA polymerase. J Biol Chem 1989, 264:20552-20560.

23. Sedman T, Kuusk S, Kivi S, Sedman J: A DNA helicase required for maintenance of the functional mitochondrial genome in Saccharomyces cerevisiae. Mol Cell Biol 2000, 20:1816-1824.

24. Lahaye A, Stahl H, Thines-Sempoux D, Foury F: PIFI: a DNA helicase in yeast mitochondria. EMBO J 1991, 10:997-1007.

25. Vongsamphanh R, Fortier PK, Ramotar D: Pir Ip mediates translocation of the yeast Apn Ip endonuclease into the mitochondria to maintain genomic stability. Mol Cell Biol 200I, 21:1647-1655.

26. Chen XJ, Wang X, Kaufman BA, Butow RA: Aconitase couples metabolic regulation to mitochondrial DNA maintenance. Science 2005, 307:7|4-717.

27. Myers AM, Pape LK, Tzagoloff A: Mitochondrial protein synthesis is required for maintenance of intact mitochondrial genomes in Saccharomyces cerevisiae. EMBO J 1985, 4:2087-2092.

28. Paul MF, Velours J, Arselin de Chateaubodeau G, Aigle M, Guerin B: The role of subunit 4 , a nuclear-encoded protein of the $F_{0}$ sector of yeast mitochondrial ATP synthase, in the assembly of the whole complex. Eur J Biochem 1989, 185:163-171.

29. Duvezin-Caubet S, Rak M, Lefebvre-Legendre L, Tetaud E, Bonnefoy N, di Rago JP: A "petite obligate" mutant of Saccharomyces cerevisiae : functional mtDNA is lethal in cells lacking the delta subunit of mitochondrial $\mathbf{F}_{1}$-ATPase. J Biol Chem 2006, 28I:|6305-|63|3.

30. Jones BA, Fangman WL: Mitochondrial DNA maintenance in yeast requires a protein containing a region related to the GTP-binding domain of dynamin. Genes Dev 1992, 6:380-389.

31. Merz S, Hammermeister M, Altmann K, Dürr M, Westermann B: Molecular machinery of mitochondrial dynamics in yeast. Biol Chem 2007, 388:917-926.

32. Wong ED, Wagner JA, Gorsich SW, McCaffery JM, Shaw JM, Nunnari J: The dynamin-related GTPase, Mgm lp, is an intermembrane space protein required for maintenance of fusion competent mitochondria. J Cell Biol 2000, I5 I:34I-352.

33. Carroll CW, Morgan DO: The Docl subunit is a processivity factor for the anaphase-promoting complex. Nat Cell Biol 2002, 4:880-887.

34. Reinders J, Zahedi RP, Pfanner N, Meisinger C, Sickmann A: Toward the complete yeast mitochondrial proteome: multidimensional separation techniques for mitochondrial proteomics. J Proteome Res 2006, 5:I543-1554.

35. Huh WK, Falvo JV, Gerke LC, Carroll AS, Howson RW, Weissman JS, O'Shea EK: Global analysis of protein localization in budding yeast. Nature 2003, 425:686-69I.

36. Dimmer KS, Jakobs S, Vogel F, Altmann K, Westermann B: Mdm3I and $M d m 32$ are inner membrane proteins required for maintenance of mitochondrial shape and stability of mitochondrial DNA nucleoids in yeast. J Cell Biol 2005, I68: I03-I I5.

37. Towpik J: Regulation of mitochondrial translation in yeast. Cell Mol Biol Lett 2005, 10:57I-594.

38. Rapaport $D$, Brunner M, Neupert W, Westermann B: Fzolp is a mitochondrial outer membrane protein essential for the biogenesis of functional mitochondria in Saccharomyces cerevisiae. I Biol Chem 1998, 273:20I50-20I55.

39. Hermann GJ, Thatcher JW, Mills JP, Hales KG, Fuller MT, Nunnari J, Shaw JM: Mitochondrial fusion in yeast requires the transmembrane GTPase Fzolp. / Cell Biol 1998, I 43:359-373.

40. Ling $F$, Shibata $T$ : Recombination-dependent mtDNA partitioning: in vivo role of $\mathrm{Mhrlp}$ to promote pairing of homologous DNA. EMBO J 2002, 21:4730-4740.

4I. Reenan RA, Kolodner RD: Characterization of insertion mutations in the Saccharomyces cerevisiae $\mathrm{MSHI}$ and $\mathrm{MSH} 2$ genes: evidence for separate mitochondrial and nuclear functions. Genetics 1992, 132:975-985.

42. Meeusen S, Tieu Q, Wong E, Weiss E, Schieltz D, Yates JR, Nunnari
J: Mgmlolp is a novel component of the mitochondrial nucleoid that binds DNA and is required for the repair of oxidatively damaged mitochondrial DNA. J Cell Biol 1999, | 45:29|-304.

43. Zambrano A, Fontanesi F, Solans A, de Oliveira RL, Fox TD, Tzagoloff A, Barrientos A: Aberrant translation of cytochrome c oxidase subunit I mRNA species in the absence of Mss5 Ip in the yeast Saccharomyces cerevisiae. Mol Biol Cell 2007, 18:523-535.

44. Ackerman SH, Gatti DL, Gellefors P, Douglas MG, Tzagoloff A ATPI3, a nuclear gene of Saccharomyces cerevisiae essential for the expression of subunit 9 of the mitochondrial ATPase. FEBS Lett |99|, 278:234-238.

45. Rödel G: Two yeast nuclear genes, CBSI and CBS2, are required for translation of mitochondrial transcripts bearing the 5'-untranslated COB leader. Curr Genet 1986, I I:4 I-45.

46. Kreike J, Schulze M, Pillar T, Korte A, Rödel G: Cloning of a nuclear gene MRSI involved in the excision of a single group I intron (bl3) from the mitochondrial COB transcript in S. cerevisiae. Curr Genet 1986, I I:|85-191.

47. Perez-Martinez X, Broadley SA, Fox TD: Mss5 I p promotes mitochondrial CoxIp synthesis and interacts with newly synthesized Cox Ip. EMBO J 2003, 22:595I-596I.

48. Costanzo MC, Seaver EC, Fox TD: The PET54 gene of Saccharomyces cerevisiae: characterization of a nuclear gene encoding a mitochondrial translational activator and subcellular localization of its product. Genetics 1989, I 22:297-305.

49. Valencik ML, Kloeckener-Gruissem B, Poyton RO, McEwen JE: Disruption of the yeast nuclear PET54 gene blocks excision of mitochondrial intron al5 beta from pre-mRNA for cytochrome c oxidase subunit I. EMBO J 1989, 8:3899-3904.

50. Costanzo MC, Fox TD: Product of Saccharomyces cerevisiae nuclear gene PET494 activates translation of a specific mitochondrial mRNA. Mol Cell Biol 1986, 6:3694-3703.

5I. Marbois B, Gin P, Faull KF, Poon WW, Lee PT, Strahan J, Shepherd JN, Clarke CF: Coq3 and Coq4 define a polypeptide complex in yeast mitochondria for the biosynthesis of coenzyme $Q$. J Biol Chem 2005, 280:2023I-20238.

52. Dumont ME, Ernst JF, Hampsey DM, Sherman F: Identification and sequence of the gene encoding cytochrome $c$ heme lyase in the yeast Saccharomyces cerevisiae. EMBO J 1987, 6:235-24I.

53. Graham LA, Hill KJ, Stevens TH: VMA8 encodes a 32-kDa VI subunit of the Saccharomyces cerevisiae vacuolar $\mathrm{H}(+)$-ATPase required for function and assembly of the enzyme complex. J Biol Chem 1995, 270: I5037-I5044.

54. Klionsky DJ, Herman PK, Emr SD: The fungal vacuole: composition, function, and biogenesis. Microbiol Rev 1990, 54:266-292.

55. Kane PM: The where, when, and how of organelle acidification by the yeast vacuolar H+-ATPase. Microbiol Mol Biol Rev 2006, 70:177-19|

56. Kane PM: The long physiological reach of the yeast vacuolar $\mathbf{H}^{+}$-ATPase. J Bioenerg Biomembr 2007, 39:4I5-42I.

57. Thorpe GW, Fong CS, Alic N, Higgins VJ, Dawes IW: Cells have distinct mechanisms to maintain protection against different reactive oxygen species: oxidative-stress-response genes. Proc Natl Acad Sci USA 2004, 1 0 I:6564-6569.

58. Milgrom E, Diab H, Middleton F, Kane PM: Loss of vacuolar proton-translocating ATPase activity in yeast results in chronic oxidative stress. J Biol Chem 2007, 282:7|25-7| 36.

59. Kissova I, Salin B, Schaeffer J, Bhatia S, Manon S, Camougrand N Selective and non-selective autophagic degradation of mitochondria in yeast. Autophagy 2007, 3:329-336.

60. Nobrega MP, Nobrega FG, Tzagoloff A: COXIO codes for a protein homologous to the ORFI product of Paracoccus denitrificans and is required for the synthesis of yeast cytochrome oxidase. J Biol Chem 1990, 265:14220-14226.

61. Tzagoloff A, Nobrega M, Gorman N, Sinclair P: On the functions of the yeast $\mathrm{COXIO}$ and $\mathrm{COX} I \mathrm{I}$ gene products. Biochem $\mathrm{Mol} \mathrm{BiO}$ Int 1993, 31:593-598.

62. Nobrega MP, Bandeira SC, Beers J, Tzagoloff A: Characterization of $\operatorname{COX} 19$, a widely distributed gene required for expression of mitochondrial cytochrome oxidase. J Biol Chem 2002, 277:40206-40211.

63. Broadley SA, Demlow CM, Fox TD: Peripheral mitochondrial inner membrane protein, Mss2p, required for export of the mitochondrially coded Cox $2 \mathrm{p} \mathrm{C}$ tail in Saccharomyces cerevisiae. Mol Cell Biol 200I, 21:7663-7672.

64. Carlson CG, Barrientos A, Tzagoloff A, Glerum DM: COXI6 encodes a novel protein required for the assembly of cyto- 
chrome oxidase in Saccharomyces cerevisiae. J Biol Chem 2003, 278:3770-3775.

65. Kaeberlein M, Burtner CR, Kennedy BK: Recent developments in yeast aging. PLoS Genet 2007, 3:e84.

66. Balaban RS, Nemoto S, Finkel T: Mitochondria, oxidants, and aging. Cell 2005, I 20:483-495.

67. Madeo F, Fröhlich E, Ligr M, Grey M, Sigrist SJ, Wolf DH, Fröhlich KU: Oxygen stress: a regulator of apoptosis in yeast. J Cell Biol 1999, I 45:757-767.

68. Andrés C, Lurin C, Small ID: The multifarious roles of PPR proteins in plant mitochondrial gene expression. Physiol Plant 2007, 129:14-22.

69. Claros MG, Vincens P: Computational method to predict mitochondrially imported proteins and their targeting sequences. Eur J Biochem 1996, 241:779-786.

70. Hess DC, Myers CL, Huttenhower C, Hibbs MA, Hayes AP, Paw J, Clore JJ, Mendoza RM, Luis BS, Nislow C, Giaever G, Costanzo M, Troyanskaya OG, Caudy AA: Computationally driven, quantitative experiments discover genes required for mitochondrial biogenesis. PLoS Genet 2009, 5: l 000407.

7I. Morris TW, Reed KE, Cronan JEJ: Identification of the gene encoding lipoate-protein ligase A of Escherichia coli. J Biol Chem 1994, 269:16091-16100.

72. Schonauer MS, Kastaniotis AJ, Hiltunen JK, Dieckmann CL: Intersection of RNA processing and the type II fatty acid synthesis pathway in yeast mitochondria. Mol Cell Biol 2008 , 28:6646-6657

73. Alvaro D, Lisby M, Rothstein R: Genome-wide analysis of Rad52 foci reveals diverse mechanisms impacting recombination. PLoS Genet 2007, 3:e228.

74. Federovitch $\mathrm{CM}$, Jones $\mathrm{YZ}$, Tong $\mathrm{AH}$, Boone $\mathrm{C}$, Prinz WA, Hampton RY: Genetic and structural analysis of Hmg2p-induced ER remodeling in S. cerevisiae. Mol Biol Cell 2008, I 9:4506-4520.

75. Osman C, Haag M, Potting C, Rodenfels J, Dip PV, Wieland FT, Brügger $B$, Westermann B, Langer T: The genetic interactome of prohibitins links their function to cardiolipin and phosphatidylethanolamine in mitochondria. J Cell Biol 2009, I 84:583-596.

76. Dilda PJ, Don AS, Tanabe KM, Higgins VJ, Allen JD, Dawes IW, Hogg $P$ ]: Mechanism of selectivity of an angiogenesis inhibitor from screening a genome-wide set of Saccharomyces cerevisiae deletion strains. I Natl Cancer Inst 2005, 97:|539-| 547.

77. Steinmetz LM, Scharfe C, Deutschbauer AM, Mokranjac D, Herman ZS, Jones T, Chu AM, Giaever G, Prokisch H, Oefner PJ, Davis RW: Systematic screen for human disease genes in yeast. Nat Genet 2002, 3 I:400-404.

78. Prokisch H, Scharfe C, Camp DG 2nd, Xiao W, David L, Andreoli C, Monroe ME, Moore RJ, Gritsenko MA, Kozany C, Hixson KK, Mottaz HM, Zischka H, Ueffing M, Herman ZS, Davis RW, Meitinger T, Oefner PJ, Smith RD, Steinmetz LM: Integrative analysis of the mitochondrial proteome in yeast. PLOS Biol 2004, 2:el 60.

79. Perocchi F, Jensen LJ, Gagneur J, Ahting U, von Mering C, Bork P, Prokisch $H$, Steinmetz LM: Assessing systems properties of yeast mitochondria through an interaction map of the organelle. PLoS Genet 2006, 2:el 70.

80. Lettier G, Feng $Q$, de Mayolo AA, Erdeniz N, Reid RJ, Lisby M, Mortensen UH, Rothstein R: The role of DNA double-strand breaks in spontaneous homologous recombination in $S$. cerevisiae. PLoS Genet 2006, 2: el 94.

81. Sikorski RS, Hieter P: A system of shuttle vectors and host strains designed for efficient manipulation of DNA in Saccharomyces cerevisiae. Genetics 1989, 122:19-27.

82. Sherman F: Getting started with yeast. Methods Enzymol 1991, I 94:3-2I.

83. Westermann B, Herrmann JM, Neupert W: Analysis of mitochondrial translation products in vivo and in organello in yeast. Methods Cell Biol 200I, 65:429-438.

84. Truong D, Gietz R: Yeast transformation. Methods Microbiol 2007, 36:45-54.

85. Livak KJ, Schmittgen TD: Analysis of relative gene expression data using real-time quantitative PCR and the 2(-Delta Delta C(T)) Method. Methods 200I, 25:402-408. 